\title{
Comparison of the diurnal variations of warm-season precipitation for East Asia vs. North America downstream of the Tibetan Plateau vs. the Rocky Mountains
}

\author{
Yuanchun Zhang ${ }^{1,2}$, Fuqing Zhang ${ }^{2}$, and Jianhua Sun ${ }^{1}$ \\ ${ }^{1}$ Institute of Atmospheric Physics, Chinese Academy of Sciences, Beijing, China \\ ${ }^{2}$ Department of Meteorology, The Pennsylvania State University, University Park, Pennsylvania, USA \\ Correspondence to: Fuqing Zhang (fzhang@psu.edu) and Jianhua Sun (sjh@mail.iap.ac.cn) \\ Received: 19 April 2014 - Published in Atmos. Chem. Phys. Discuss.: 27 May 2014 \\ Revised: 13 August 2014 - Accepted: 4 September 2014 - Published: 13 October 2014
}

\begin{abstract}
A wave-number-frequency spectral decomposition technique is used to analyze the high-resolution NOAA/Climate Prediction Center morphing technique (CMORPH) precipitation data set and to explore the differences and similarities of the diurnal variation of warm-season precipitation in the East Asia and North America downstream of big topography. The predominant phase speed of precipitation at different time scales for North America, averaged over all warm-season months (May-August) for 2003-2010, is $\sim 20 \mathrm{~ms}^{-1}$, which is faster than the speed of $\sim 14 \mathrm{~ms}^{-1}$ calculated for East Asia. Consistent with the recent studies of the precipitation diurnal cycles for these two regions, the difference in the diurnal phase propagation is likely due to the difference in the mean steering level wind speed for these two regions. The wave-number-frequency spectral analysis further reveals the complex, multi-scale, multi-modal nature of the warm-season precipitation variation embedded within the diurnal cycle over both continents, with phase speeds varying from 10 to $30 \mathrm{~ms}^{-1}$ and wave periods varying from diurnal to a few hours. At the diurnal frequency regulated by the thermodynamically driven mountains-plains solenoids (MPSs), increased precipitation for both continents first originates in the afternoon from the eastern edge of big topography and subsequently moves downslope in the evening and reaches the broad plains area at night. More complex diurnal evolutions are observed in East Asia due to the more complex, multistep terrains east of the Tibetan Plateau and the associated localized MPS circulations. Nevertheless, increased variation of precipitation
\end{abstract}

at smaller spatial and temporal scales is evident in the active phase of the dominant diurnal cycle for both continents.

\section{Introduction}

Previous studies have noted that warm-season convection in the northern hemisphere often forms over the high mountains during the afternoon and subsequently propagates eastward across the lee-side plains overnight due to diurnal changes in diabatic heating between regions with different surface topography (Ding, 1993; Geng and Yamada, 2007; Carbone et al., 2002, hereafter, CAR02; Carbone and Turtle, 2008; Trier et al., 2006, 2010; Wang et al., 2004, 2005; He and Zhang, 2010, hereafter HZ10; Huang et al., 2010; Bao et al., 2011, hereafter BZS11). The terrains of both East Asia and North America feature a western plateau (mountainous region) and an eastern low-lying plain. In East Asia (Fig. 1a), the "first-step" terrain is the Tibetan Plateau (TP). The "second-step" terrain generally refers to the high mountain ranges such as the Da Hinggan Mountains in northeastern China, the Yanshan Mountains, the Taihangshan Mountains, the Loess Plateau and the Mongolian Plateau in northern China, the Qinling Mountains in Central China, and the Yungui Plateau in southwestern China. The "third-step" terrain (hereafter referred to as the east plains) includes the low-lying plains and hilly regions to the east of the secondstep terrain, the high-mountain terrains. In North America, the terrain elevation distribution includes the Rocky Mountains, the central plains and the Appalachian Mountains from 


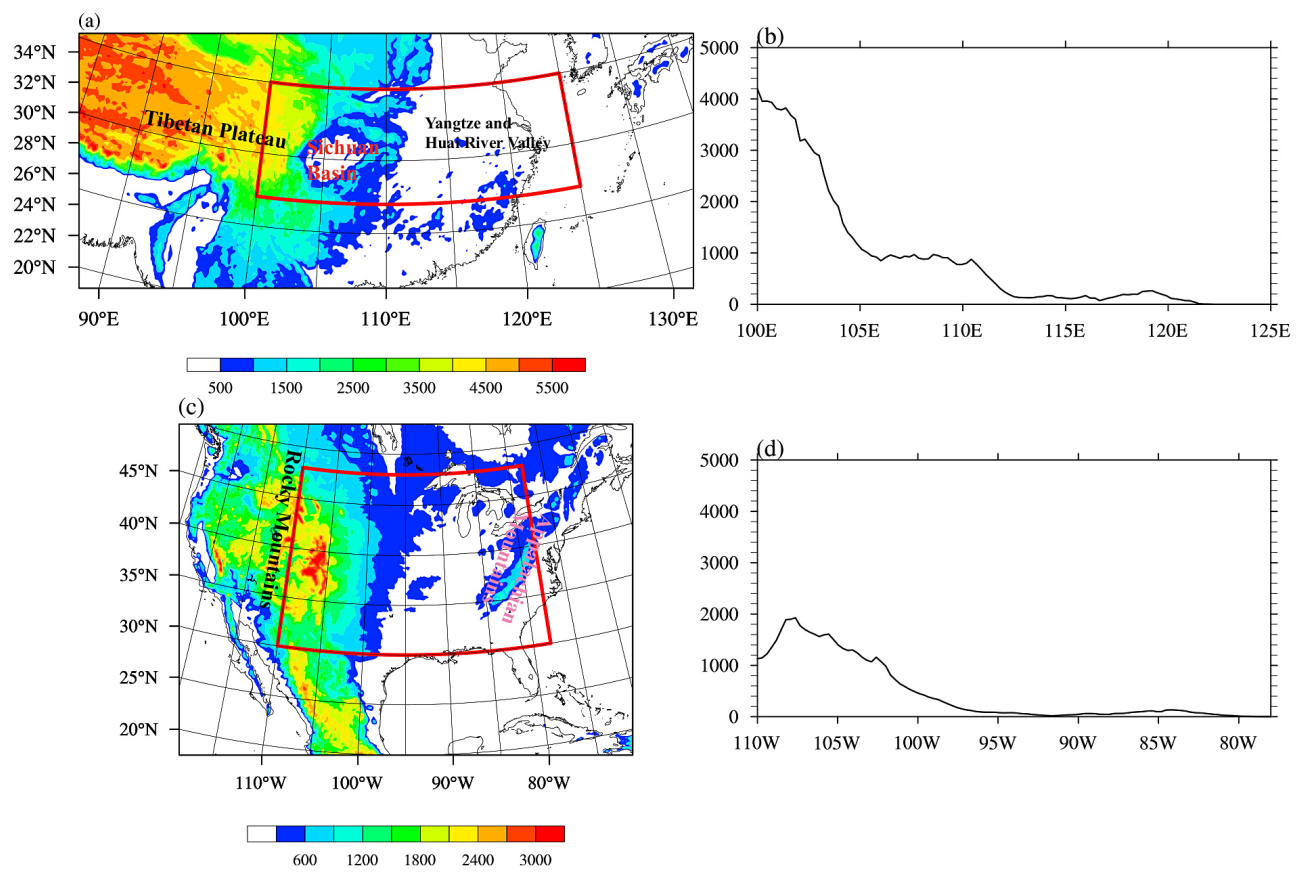

Figure 1. Map distributions of the terrain elevations over (a) East Asia and (c) North America with the red boxes denoting the focus domains (shadings, units: $\mathrm{m}$ ). The right panels are the meridional averages of the terrain elevations over the focus domains for (b) East Asia and (d) North America.

west to east (Fig. 1b). The diurnal cycle of warm-season rainfall in the US is characterized by afternoon maxima over the Rocky Mountains and midnight maxima over the region east of the Rocky Mountains and the adjacent plains (Dai et al., 1999). Carbone et al. (2002) used a radar-based data set to demonstrate the delayed-phase diurnal signal of the precipitation from the western cordillera, and the zonal phasespeed range of rain streaks $(\sim 1000 \mathrm{~km}$ and $20 \mathrm{~h})$ propagating eastward from the eastern edge of the Rocky Mountains is between 7 and $30 \mathrm{~ms}^{-1}$, with a median phase speed of $14 \mathrm{~ms}^{-1}$. High-resolution convection-permitting simulations also show similar eastward propagation of precipitation over the US (Trier et al., 2006). Over the "three-step" terrain in East Asia, the summer precipitation on the TP maximizes in the afternoon to early evening, and nocturnal rainfall occurs over the Sichuan Basin (SCB) areas and precipitation phase delays over the low-lying plains (Tao, 1980; Ninomiya, 2000; Asai et al., 1998; Wang et al., 2004, 2005; Yasunari and Miwa, 2006; Bao et al., 2011; Xu and Zipser, 2009, 2011; Sun et al., 2010; Yu et al., 2007, 2009). Wang et al. $(2004,2005)$ used hourly infrared (IR) brightness temperatures observed by the Geostationary Meteorological Satellite (GMS) to compile a climatology of warmseason cloud/precipitation episodes over East Asia; they found that the propagating events moved eastward at phase speed of $\sim 10-25 \mathrm{~ms}^{-1}$ and compared the similarity of cloud/precipitation events to the rain streaks in CAR02. Recent studies have explored diurnal variation of precipitation using the National Oceanic and Atmospheric Administration (NOAA) Climate Prediction Center(CPC) morphing technique (CMORPH) rainfall data set and have shown that precipitation propagates downslope, eastward/southeastward, at a speed of $\sim 13 \mathrm{~ms}^{-1}$ from the eastern edge of the TP, the second-step terrain in northern China (He and Zhang, 2010; BZS11; Sun and Zhang, 2012). Through convectionpermitting simulations that successfully captured the diurnal precipitation propagation, Bao and Zhang (2013) further investigated what controls the diurnal peak propagation speed. Consistent with Trier et al. (2010), they found that besides the impact of the mountains-plains solenoids (MPSs), the steering-level mean flow and the cold pool dynamics both play an essential role in the propagation and maintenance of the precipitation peak over the plains.

Some studies have demonstrated, using harmonic analysis in the temporal dimension, that diurnal and semi-diurnal oscillations are major factors in determining the sub-daily variation in precipitation over most of eastern China (Dai, 1999; Zhou et al., 2008; Huang and Chan, 2012; Wang et al., 2004, 2005). CAR02 also performed one-dimensional harmonic decomposition of propagating precipitation events and found that the principal signals resulting from phaselocked events are diurnal forcing over both cordilleras and semidiurnal forcing between the cordilleras. The above studies only analyzed the multi-scale features of precipitation in the temporal dimension. Wheeler and Kiladis (1999, hereafter WK99) used wave-number-frequency power spectral 
analysis to extract the different convectively coupled equatorial waves by filtering the satellite-observed outgoing longwave radiation (OLR) data set for specific zonal wave numbers and frequencies. Lane and Zhang (2011) applied a similar method to an idealized cloud-system resolving model simulation to examine the coupling between a tropical cloud population and mesoscale gravity waves. Considering the multi-scale and multi-modal nature of precipitation in the zonal, spatial, and temporal dimensions east of the TP and the Rocky Mountains, this work attempts to decompose precipitation using the aforementioned wave-number-frequency power spectral analysis method (WK99) that was originally developed for studying tropical waves and convection.

The primary objectives of this study are to apply the twodimensional wave-number-frequency power spectral analysis and decomposition to systematically examine the multiscale characteristics of the (extratropical, continental) summertime precipitation in East Asia and North America, for the first time to directly compare the diurnal variation and phase propagation of warm-season precipitation over these regions with the same data set, to explore the roles of the MPSs and the steering-level mean flow in driving the similarities and differences of summertime rainfall evolution over these two continents.

Section 2 describes the data and wave-number-frequency methodology. Differences and similarities in the diurnal variation of the precipitation during the warm seasons of East Asia and North America are shown in Sect. 3. Section 4 compares the precipitation power spectra of the two continents. Section 5 analyzes the diurnal variations of filtered precipitation within different filtering domains. Finally, conclusions and discussion are included in Sect. 6.

\section{Data and methodology}

\subsection{Data and analysis domain}

The primary data set used in this work is the high temporal and spatial resolution global precipitation data set over 2003-2010 from the National Oceanic and Atmospheric Administration (NOAA) Climate Prediction Center (CPC) morphing technique (CMOPRH; Joyce et al., 2004) and NCEP FNL (Final Operational Global Analysis data $1^{\circ} \times 1^{\circ}$ ). The CMORPH data set was used recently by $\mathrm{He}$ and Zhang (2010), BZS11 and Sun and Zhang (2012) to study the diurnal evolution of the summertime precipitation over East Asia (regions lee of the TP) but has not been systematically applied over North American (regions downstream of the Rocky Mountains). One advantage of the CMORPH data is their spatial and temporal homogeneity and continuity, which along the rather high temporal and spatial resolution (available every $30 \mathrm{~min}$ and every $0.07^{\circ} \times 0.07^{\circ}$ degree in lat/lon) can be used to directly compare the similarities and difference of the diurnal variations of rainfall pre- cipitation between the two continents. Previous studies using satellite infrared brightness temperature as a proxy of rainfall or convection found some similarities of diurnal evolution over East Asia (Wang et al., 2004, 2005) to those over North America derived from the radar reflectivity composite (CAR02).

The two analysis domains are shown in Fig. 1a and c. The East Asian domain is $100-125^{\circ} \mathrm{E}$ and $27-35^{\circ} \mathrm{N}$ and includes the area from the eastern Tibetan Plateau (TP), the Sichuan Basin areas, and the Qinling and Wushan Mountains to the low-lying, mid-lower ranges of the Yangtze and Huai River valley (YHRV) and some adjacent oceanic areas on the eastern edge of the domain. The North American domain (110 $78^{\circ} \mathrm{W}, 30-48^{\circ} \mathrm{N}$; the latitudinal range is wider than that of East Asian domain) covers most of the continent including the Rocky Mountains, the Great Plains and part of the Appalachian Mountains. The meridional average terrain elevations (Fig. 1b and d) clearly show that there are three steps in the averaged terrain elevation from the west to the east (TP, the second-step highlands and eastern low-lying plains) in East Asia.

Based on the position of the primary rain belt over East Asia during the rainy season, BZS11 divides the warm season into three periods: the pre-Meiyu period (15 May to 15 June), the Meiyu period (15 June to 15 July), and the post-Meiyu period (15 July to 15 August). CAR02 defines the warm season as May to August. For better comparison of our work with previous studies, the warm season in East Asia was defined as 15 May to 15 August, and the time sequence for North America is the entire months of May through August.

\subsection{Wave-number-frequency spectral analysis and decomposition}

To more systematically examine the multi-scale and multimodal nature of the eastward-propagating diurnal precipitation, a wave-number-frequency spectral analysis method is applied in this study. This space-time spectral analysis and decomposition technique is particularly useful for the study of complex phenomena such as large-scale tropical convection that contain multiple spatial and temporal scales (WK99; Hayashi, 1982). The technique has also been applied to study smaller-scale waves and convection (e.g., Lane and Zhang, 2011).

The spatial domain for the power spectral analysis is for the longitude domain between 90 and $132^{\circ} \mathrm{E}$ for the CMORPH data at each latitude from 27 to $35^{\circ} \mathrm{N}$ for East Asia, and between 72 and $120^{\circ} \mathrm{W}$ at each latitude from 30 to $48^{\circ} \mathrm{N}$ for North America. To minimize the effect of the lateral domain boundaries, the focus domains for direct comparison that are highlighted in Fig. 1a and c are slightly smaller than the domains used for the spectral analysis.

In the time domain, since we are primarily interested in the diurnal periods or shorter, the spectral analysis is performed over 91 (121) consecutive $48 \mathrm{~h}$ segments of the 8 -year-mean 

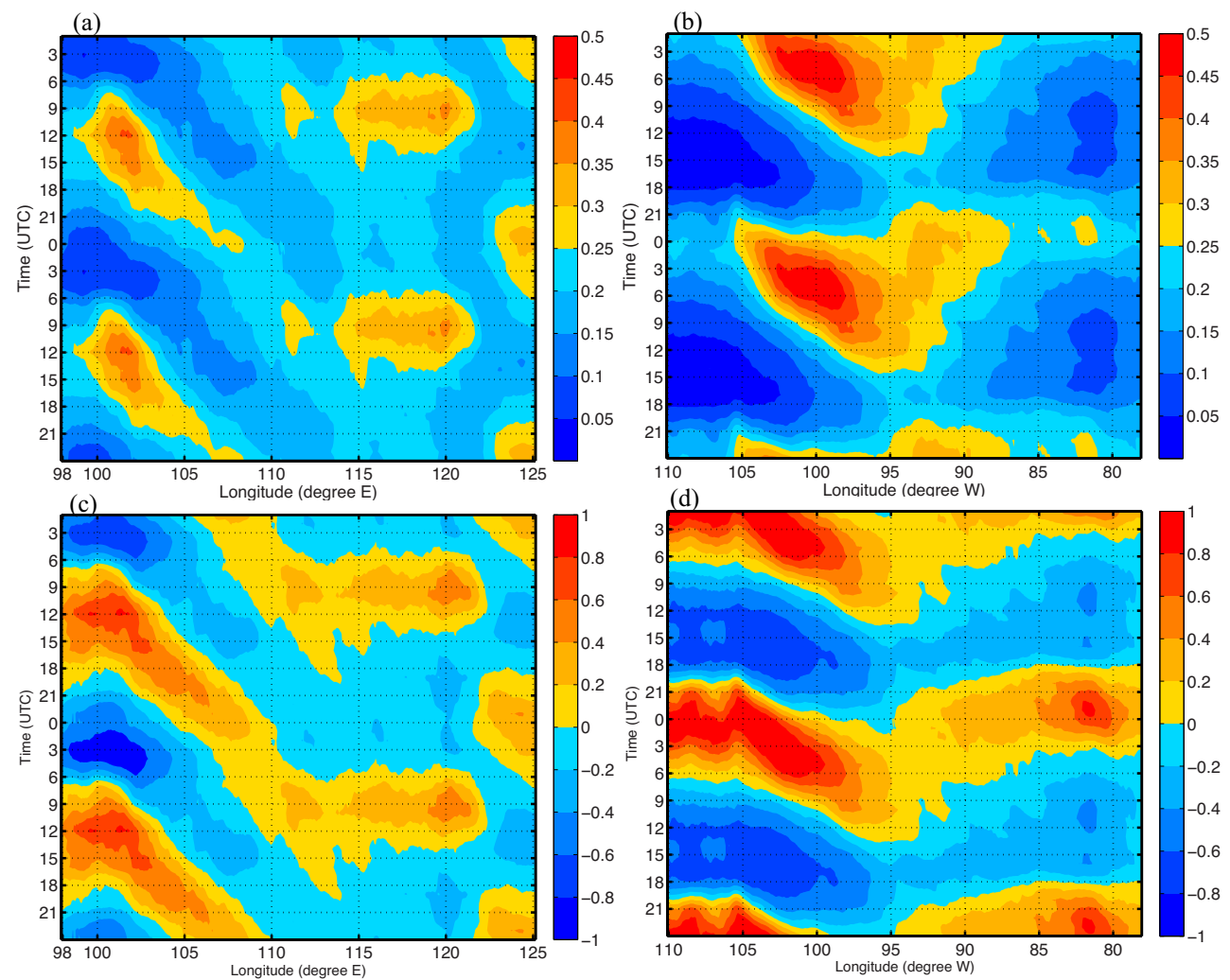

Figure 2. Top: Time-longitude diagrams of the warm-season hourly mean precipitation (units: $\mathrm{mmh}^{-1}$ ) over the focus domains for (a) East Asia and (b) North America. Bottom: time longitude diagrams of the warm-season normalized hourly mean precipitation averaged meridionally over the focus domains for (c) East Asia and (d) North America.

hourly warm-season CMORPH data set from 15 May to 15 August (from 1 May to 31 August) for East Asia (North America), with a $24 \mathrm{~h}$ overlap between two neighboring analysis segments (similar time segmenting procedure is also used in WK99).

The two-dimensional fast Fourier transform (fft2) function in MATLAB $^{\odot}$ is used for the spectral analysis simultaneously in the time and spatial domains specified above. After the power spectra are calculated for each $48 \mathrm{~h}$ segment and at every latitude, the time-mean spectrum is derived averaged over all the $48 \mathrm{~h}$ power spectra segments in each region. The final power spectrum is the sum of all the power spectra at every latitude.

To further show the map distribution and evolution of the filtered precipitation at selected spatial and temporal scales, the wave-number-frequency decomposition of the precipitation data is obtained by using the inverse 2-D fast Fourier transform (ifft2) function in MATLAB ${ }^{\odot}$. The spectral range of interest is selected based on the power spectra in wavenumber-frequency domain. Different from using the overlapping time segment for the power spectra computation, the forward process (FFT2D) for each latitude before IFFT2D in the wave-number-frequency decomposition is calculated for the entire warm season to capture the individual propagations.

\section{Diurnal variation of warm-season precipitation and MPS circulations}

\subsection{Diurnal variation of eastward-propagating precipitation}

Figure 2 shows time-longitude diagrams of hourly precipitation and normalized hourly precipitation ${ }^{1}$ during the warm season in East Asia and North America, and the horizontal distributions of normalized hourly precipitation are presented in Figs. 3 and 4, respectively. Consistent with previous studies (Carbone et al., 2002, 2008; Wang et al., 2004; BZS11; $\mathrm{Xu}$ and Zipser, 2011), the diurnal variation of precipitation has an evident phase-delayed feature east of the big topography (TP and the Rocky Mountains, Fig. 2). The current study focuses on the multi-scale nature of this diurnal evolution, and to systematically and directly compare and understand

\footnotetext{
${ }^{1}$ Normalized hourly precipitation is calculated using $n r(t)=$ $[r(t)-\operatorname{mean}(r(t=1,24))] / \operatorname{mean}(r(t=1,24))$
} 
the similarities and differences in the rainfall diurnal variability between the two continents using the same data set.

During the warm season in East Asia (Figs. 2a and 3), the precipitation maximum first appears over the eastern edge of the TP $\left(100-103^{\circ} \mathrm{E}\right)$ in the afternoon to early evening (09:00-13:00 UTC ${ }^{2}$, Figs. 2a, 3d and e) and propagates eastward to the Sichuan Basin $\left(103-107^{\circ} \mathrm{E}\right)$ between the late evening and the early morning (18:00-21:00 UTC, Fig. 2a, $3 \mathrm{~g}$ and $\mathrm{h}$ ), which is consistent with the observation of nighttime rainfall in previous studies (Wang et al., 2004; Chen et al., 2009; Kurosaki and Kimura, 2002; BZS11). The precipitation maximum continually moves eastward at a phase speed of $\sim 14 \mathrm{~ms}^{-1}$ and arrives at the second-step terrain and its downslope $\left(\sim 110^{\circ} \mathrm{E}\right)$ in the afternoon to early evening (06:00-12:00 UTC, Fig. 2a and 3a and b). The precipitation reaches $\sim 114^{\circ} \mathrm{E}$ in the late evening to early morning ( $\sim$ 15:00-18:00 UTC), which is a continuation of the signal from the TP and the Sichuan Basin (103-107 ${ }^{\circ}$ E, Fig. 2a). In addition to the continuous eastward propagation from the eastern edge of the TP to the second-step terrain, the nonpropagating precipitation maximum occurs in the afternoon to early evening from the eastern slope of the second-step terrain $\left(\sim 110^{\circ} \mathrm{E}\right)$ to the low-lying plains $\left(115-122^{\circ} \mathrm{E}\right.$, Fig. $\left.2 \mathrm{a}\right)$, but the horizontal distributions of normalized precipitation (Fig. 3c-f) show that the phase of the diurnal variation in the normalized hourly precipitation in the northern area (north of $30^{\circ} \mathrm{N}$ ) is noticeably different from that in the southern part of the domain (south of $30^{\circ} \mathrm{N}$ ) (Fig. 3c-f). The zonal wind speed north of $30^{\circ} \mathrm{N}$ (averaged over $110-115^{\circ} \mathrm{E}$, not shown) is greater than that over the southern domain. Compared with the main low-lying plain (Figs. 2a, 3), the precipitation over the adjacent oceanic area exhibits land-sea reversal of diurnal rainfall phase, with a nighttime precipitation maximum (18:00-03:00 UTC) and a daytime minimum (09:00-15:00 UTC).

The average diurnal evolution of the normalized hourly precipitation over North America (Fig. 2b) is to a large extent consistent with previous studies of CAR02 and Carbone et al. (2008) that were derived from the radar reflectivity composite. The diurnal evolution in the current study is noticeably even better categorized with the CMORPH data set that has better spatial and temporal homogeneity and continuity. The maximum diurnal precipitation amplitude appears in the Rocky Mountains in the afternoon to early evening (18:00-00:00 UTC, Fig. 4a-g), then it propagates eastward to the eastern Rocky Mountains, with the maximum gradually weakening (Fig. $4 \mathrm{~b}$ and c), and arrives at the main plain $\left(\sim 94^{\circ} \mathrm{W}\right)$ in the early morning (Fig. $4 \mathrm{~d}$ and e). The propagation speed between 105 and $94^{\circ} \mathrm{W}$ is $\sim 20 \mathrm{~ms}^{-1}$, which is consistent with previous studies (CAR02, Trier et al., 2006). The eastward propagating signal from the eastern Rocky Mountains is suppressed at approximately $94^{\circ} \mathrm{W}$,

\footnotetext{
${ }^{2}$ The local time in this area is a couple of hours behind Beijing Jing Time (BJT) while BJT $=\mathrm{UTC}+8 \mathrm{~h}$.
}

resulting in strong afternoon-to-evening precipitation east of $90^{\circ} \mathrm{W}$. The obvious diurnal variation of precipitation, with the maximum in the local afternoon to early evening (approximately 22:00-02:00 UTC), is found east of $94^{\circ} \mathrm{W}$ (Figs. $2 \mathrm{~b}$ and $4 \mathrm{~b}-\mathrm{h})$.

However, the semi-diurnal maximum near $98-86^{\circ} \mathrm{W}$ that is shown in CAR02 is less evident in Fig. 2b (but more clear in the spectral analysis to be discussed later). The possible reasons for the different propagation phase speeds and the semi-diurnal signal are that the radar-based data set from 1997 to 2000 used in CAR02 could capture more semidiurnal signals which composite the rain streaks frequency, or there may have strong inter-annual variability in the semidiurnal variations and background flow. One difference between East Asia (Fig. 2a) and North America (Fig. 2b) is that hourly maximum precipitation originating from the eastern edge of the TP propagates to the Sichuan Basin and the low-lying plains $\left(115-122^{\circ} \mathrm{E}\right)$ of East Asia, but the eastward propagating signal from the eastern Rocky Mountains is stalled at approximately $94^{\circ} \mathrm{W}$.

In addition to that the eastward propagation of precipitation east of the Rocky Mountains in North America is similar to that east of the TP in East Asia (Figs. 2a, 3), another similarity is that the precipitation maximum appears over the eastern continent and the southeastern coastlines in the afternoon to the early evening (Figs. 3c-e and $4 \mathrm{a}-\mathrm{g}$ ), consistent with a non-propagating precipitation maximum in the afternoon over the eastern plains (Fig. 2a and b). However, the phase speed of the precipitation propagation east of the Rocky Mountains, $\sim 20 \mathrm{~ms}^{-1}$, is faster than that east of the $\mathrm{TP}, \sim 14 \mathrm{~ms}^{-1}$. The vertical profile of the regional average zonal wind speeds over our focus domains (Fig. 1) shows that the $u$-component of the mean wind from the lower to higher troposphere over North America is greater than that over East Asia (Fig. 5c). Meanwhile, over the two continents, the mean steering wind speeds within the middle troposphere $(500-400 \mathrm{hPa}$ ) is both slower than the phase speed of the precipitation propagation, which implies that other factors such as the MPSs and the cold pool dynamics may also influence the phase speed of the eastward propagation of precipitation (Bao and Zhang, 2013).

\subsection{Diurnal variation of MPS circulations}

Previous studies have discussed that mountain-plains solenoid (MPS) circulations induced by differential diabatic heating between plateaus or highlands and basins or plains could be related to the diurnal variation in the local hourly precipitation (Tripoli and Cotton, 1989a; Zhang and Koch, 2000; Koch et al., 2001; Trier et al., 2010; He and Zhang, 2010, BZS11; Bao and Zhang, 2013). Figure 6 shows the latitudinally averaged anomalous vertical motion and the vertical vector of zonal and vertical perturbation wind during the mean warm season from 2003 to 2010, which are essentially the grand averages of the three individual rainy periods 


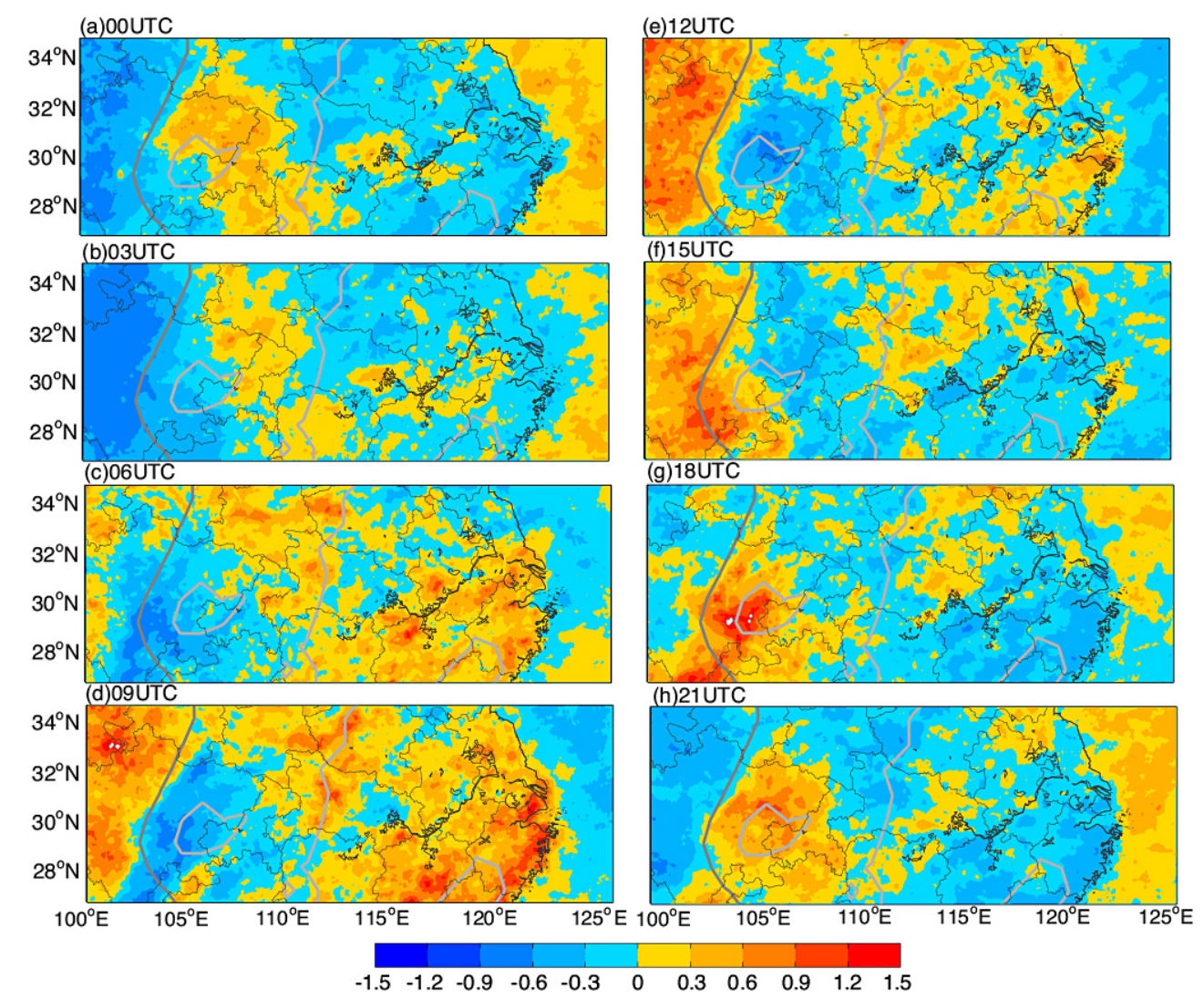

Figure 3. Map distributions of the normalized hourly mean precipitation valid at (a) 00:00, (b) 03:00, (c) 06:00, (d) 09:00, (e) 12:00, (f) 15:00, (g) 18:00 and (h) 21:00 UTC averaged over the warm season in East Asia. The darker gray line represents the terrain elevation of $5000 \mathrm{~m}$ and the lighter one of $300 \mathrm{~m}$.

plotted in Figs. 10, 13 and 16 in BZS11 for 2003-2009. At 06:00 UTC (Fig. 6b), due to the differential diabatic heating among the plateaus, highlands, plains and the adjacent ocean, there are three sub-regional MPS circulations (labeled as S1, $\mathrm{S} 2$, and S3 from west to east). There are corresponding diurnal precipitation peaks co-located with the upward vertical motion centers of each of the three MPS peaks (Fig. 3c). In the late afternoon and early evening (Fig. 6c), the three sub-regional MPS circulations consolidate into one dominant MPS circulation (S0) with a strong upward motion over the lee slopes of the TP and the downward motion over the plains and the adjacent ocean. The branch of the downward motion corresponds with the decreasing precipitation east of the second-step terrain (Fig. 3e). The MPS circulations after midnight (18:00 UTC, Fig. 6d) are nearly the reversal of those near the daytime peak heating time (Fig. 6b). The three upward branches over the Sichuan Basin, the eastern slope of the second-step terrain and the eastern coastline correspond with the three hourly precipitation maxima in Fig. $3 \mathrm{~g}$. At 00:00 UTC, the upward branch of the MPS circulation (S0) shifts to low-lying areas east of the TP, the downward branch appears over the eastern slope of the TP, and the weak down- ward vertical perturbation suppresses the precipitation developing over the eastern plains (115-120 $0^{\circ}$ E, Figs. $6 \mathrm{a}$ and $\left.3 \mathrm{a}\right)$.

Figure 7 shows the diurnal variation of the MPS circulation averaged over the focus domain in North America (Fig. 1b). At 00:00 UTC, due to the accumulated diabatic heating over the Rocky Mountains in the late afternoon, the obvious MPS circulations (S0) dominate the entire continent, with the upward motion over eastern edge of the Rocky Mountains and the downward motion over the central plains, but there is a weak positive vertical perturbation between 85 and $80^{\circ} \mathrm{W}$ (Fig. 7a), corresponding to precipitation maxima over the eastern edge of the Rocky Mountains and the southeastern coastline (Fig. 4a). At 06:00 UTC (Fig. 7b), the upward motion of the dominant MPS circulation (S0) converts over the central plains, the downward motion dominates over the mountain areas in the late evening, and another branch of downward motion covers the Appalachian Mountains, corresponding to strong precipitation from the eastern downslope of the Rocky Mountains to the central plains (Fig. 4c). At 12:00 and 18:00 UTC (Fig. 7c and d), the branches of upward motion and downward motion of the MPS circulations are much weaker than at the former two times, but the upward motion over the eastern edge of the Rocky Mountains 

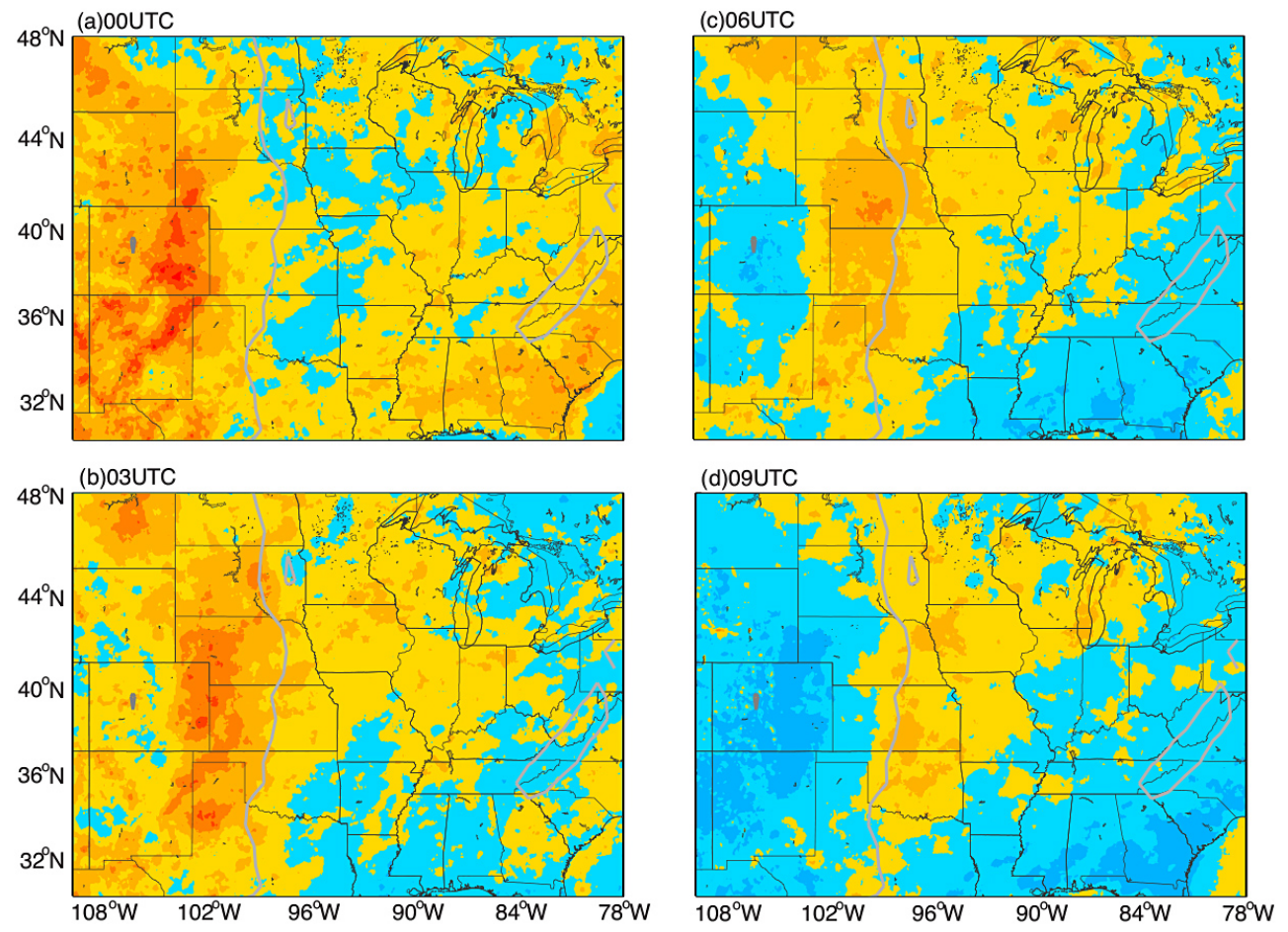

Figure 4a. Similar to Fig. 3 but normalized hourly mean precipitation over North America from 00:00 to 09:00 UTC (a-d). The darker gray line represents terrain elevation of $3000 \mathrm{~m}$ and the lighter one is $500 \mathrm{~m}$.
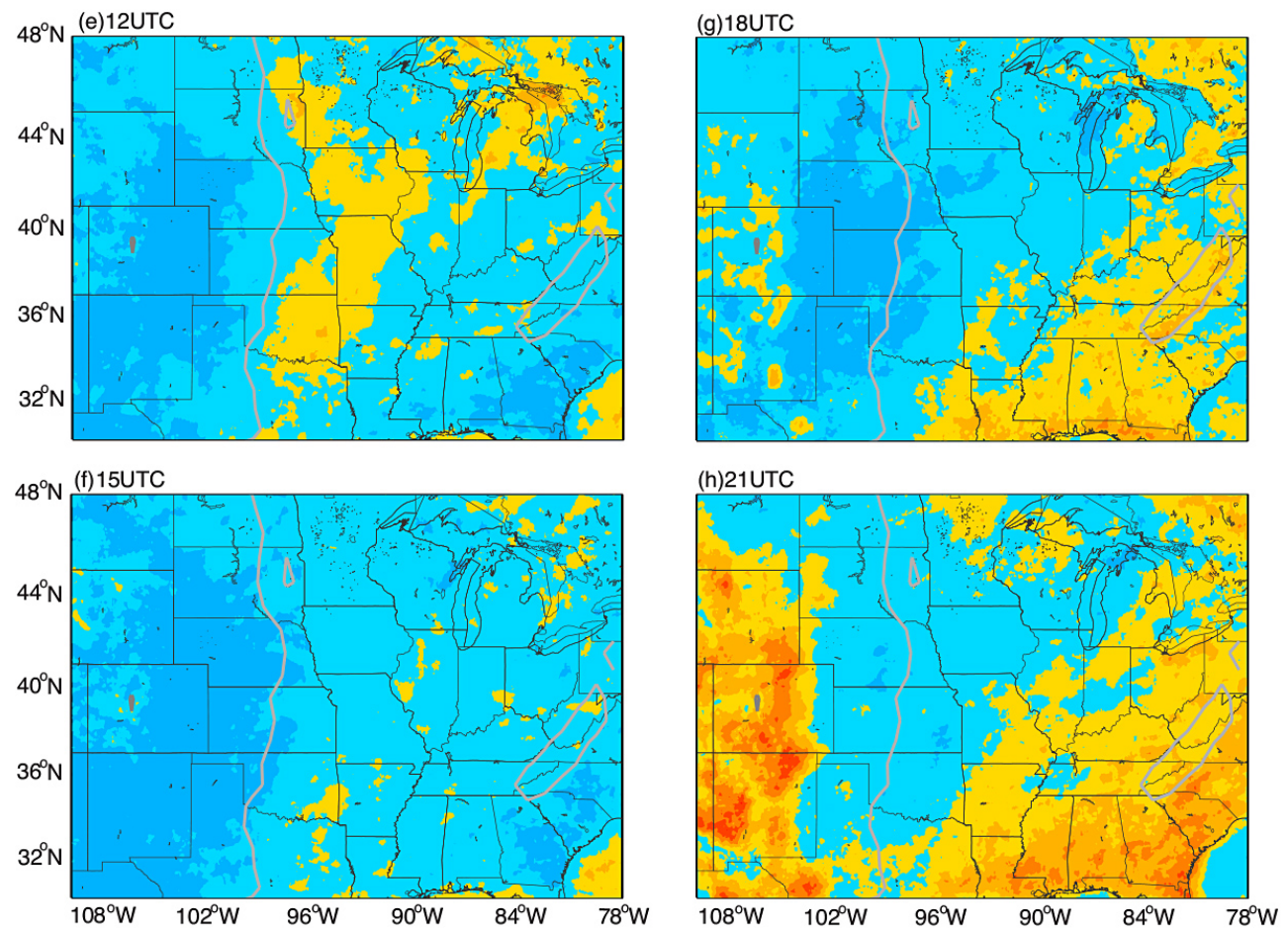

Figure 4b. Similar to Fig. 4a but from 12:00 to 21:00 UTC (e-h). 


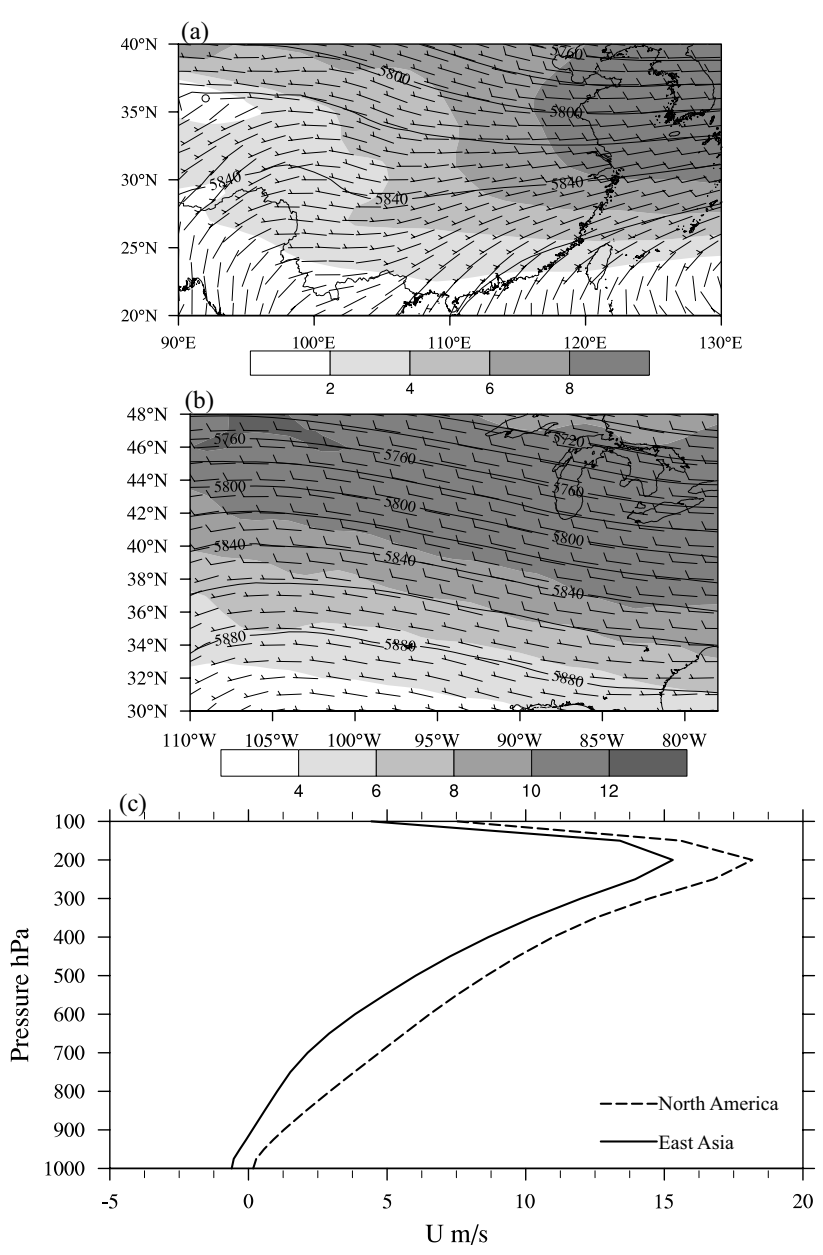

Figure 5. Map distributions of the $500 \mathrm{hPa}$ geopotential height (every 20 dam), zonal wind (shaded, units: $\mathrm{ms}^{-1}$ ) and horizontal wind barbs over (a) East Asia and (b) North America. (c) Vertical profile of the zonal mean speeds over both regions.

(100-105 $\left.{ }^{\circ} \mathrm{W}, 12: 00 \mathrm{UTC}\right)$ and the Appalachian Mountains (85-80 $\mathrm{W}, 18: 00 \mathrm{UTC})$ corresponds to the local positive precipitation perturbations in Fig. $4 \mathrm{e}$ and g. There also appears to be another weak solenoid between the Great Plains and the Appalachians (about $84-88^{\circ} \mathrm{W}$ ) at 06:00 and 18:00 UTC with a direction opposite to S0 in Carbone and Tuttle (2008).

Differential diabatic heating between the plateaus, highlands and plains over East Asia induces three sub-regionalscale $(\sim 800 \mathrm{~km})$ MPS circulations (Fig. $6 \mathrm{~b}$ and d). In North America, because of the less complicated distribution of the terrain elevation, continental-scale $(\sim 2000 \mathrm{~km})$ MPS circulation is forced by the diabatic heating contrast between the Rocky Mountains and the Central Plains (Figs. 4, 7a and $b$ ). Because of the different scales of the MPS circulations, the eastward-propagating precipitation relating to the upward branches of the MPS circulations could have different scale distributions over the two continents. To further elucidate the differences and similarities of the eastward propa- gation of precipitation within different scales over East Asia and North America and the impacts of the MPS circulations, wave-number-frequency power spectral analysis and filtering of precipitation are used in the following sections.

\section{Wave-number-frequency power spectra of hourly precipitation}

Figure 8 shows the power spectra of the hourly precipitation throughout the warm season east of the TP over East Asia and east of the Rocky Mountains over North America. The positive (negative) wave number corresponds to eastward (westward) propagating signals of precipitation. Our focus is on the eastward precipitation propagation. There are two striking, common features of the power spectra over the two continents. The first feature is the high power values in domains of low wave number ${ }^{3}$ and frequency, which is similar to the results of WK99 and LZ11. However, in contrast with the periodic spatial domains in the two previous studies, the spatial domains in this study are both non-periodic, resulting in an artificial ridge at wave-number 0 (non-zero mean) at high frequencies. The physically relevant signal is the ridge of high spectral power values, concentrated at wave-numbers $1-$ 5 and time periods longer than $12 \mathrm{~h}$, that tilts eastward, which indicates that the precipitation at a larger zonal spatial scale and a semi-diurnal to diurnal temporal scale contributes the majority of the local precipitation. To highlight the eastwardpropagation characteristics and the maximum power, following WK99 and LZ11, the raw power spectra (Fig. 8a and c) are divided by the smoothed field (Fig. $8 \mathrm{~b}$ and d) to highlight the relative peak spectra compared with the red background signals, as shown in Fig. 9. Several notable similarities can be identified in Fig. 9a and c. The first similarity is that the power maxima follow near constant lines for both continents. In the wave-number-frequency domain, the constant lines symbolize the propagation phase speeds $(c=\omega / k)$, indicating that precipitation with different zonal scales, from synoptic to mesoscale and even smaller scales, and different temporal scales, from diurnal to semi-diurnal cycles to less than $6 \mathrm{~h}$, propagates eastward at the phase-speed range, but the propagation phase speeds of precipitation are different in Fig. 9a and c.

Over East Asia, the phase-speed range is $10-25 \mathrm{~ms}^{-1}$, with a primary speed (middle solid line) of $\sim 15 \mathrm{~ms}^{-1}$ (Fig. 9a), very similar to the propagation phase speed $\left(\sim 14 \mathrm{~ms}^{-1}\right)$ evaluated directly from Fig. $2 \mathrm{a}$ and consistent with the phase speed of the propagating events averaged over $20-40^{\circ} \mathrm{N}, 95-145^{\circ} \mathrm{E}$ during May to August from 1998 to 2010 using infrared (IR) brightness temperatures (Wang et al., 2004, 2005). Figure 9b, which is the same as Fig. 9a but with the wave number from -15 to 15 to zoom in on

\footnotetext{
${ }^{3}$ Zonal wave number represents "cycles per zonal length scale $(L)$ ", here $L$ is the zonal extent of the study domains. $L$ is $4000 \mathrm{~km}$ both over East Asia and North America.
} 

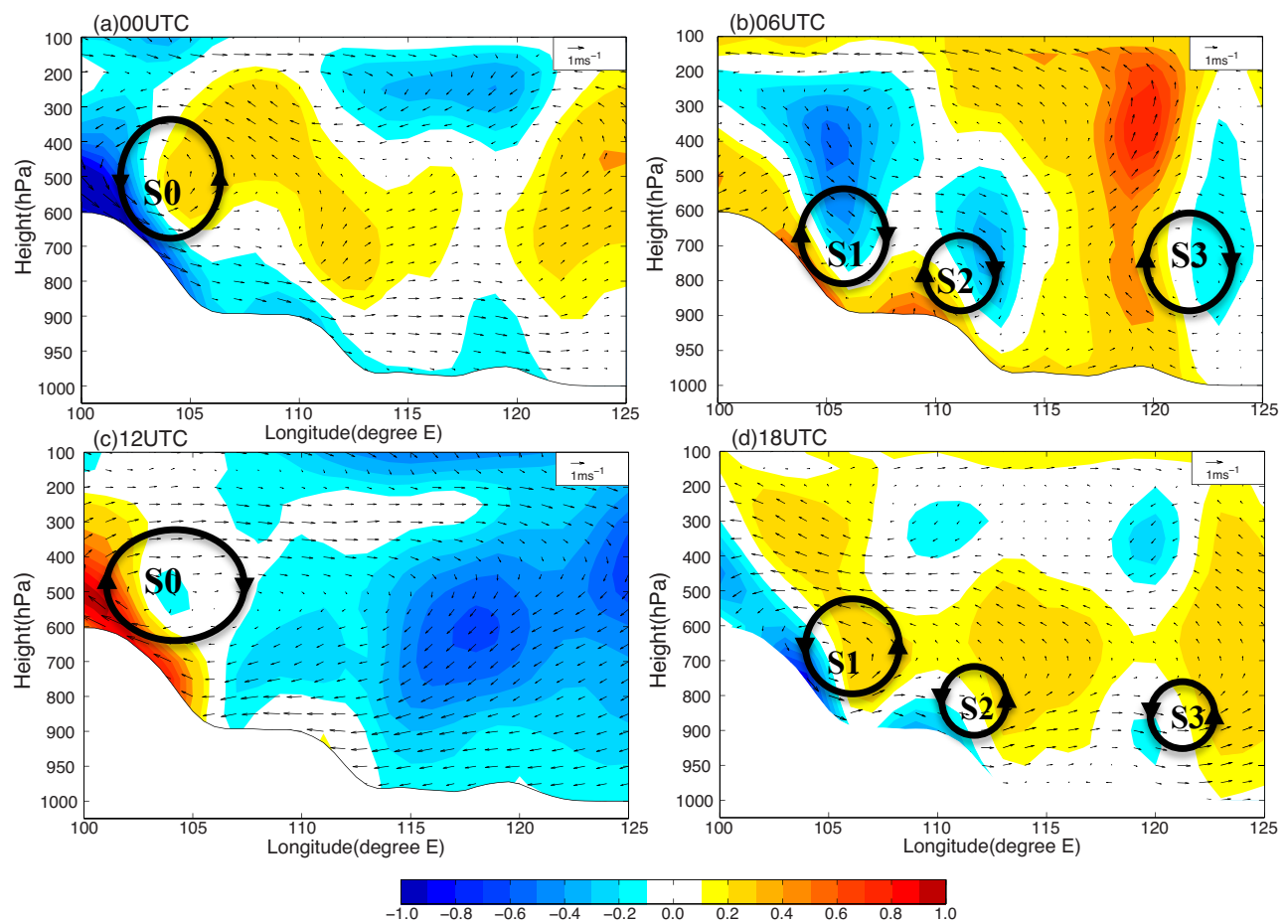

Figure 6. Vertical cross sections of the vertical motion deviations $\left(\mathrm{c} \mathrm{ms}^{-1}\right.$, shaded) and the perturbation vertical circulation vectors (zonal wind and 100x vertical velocity) averaged over the focus domain in East Asia from the warm season from 2003 to 2010 derived from the FNL analyses valid at (a) 00:00, (b) 06:00, (c) 12:00, and (d) 18:00 UTC.
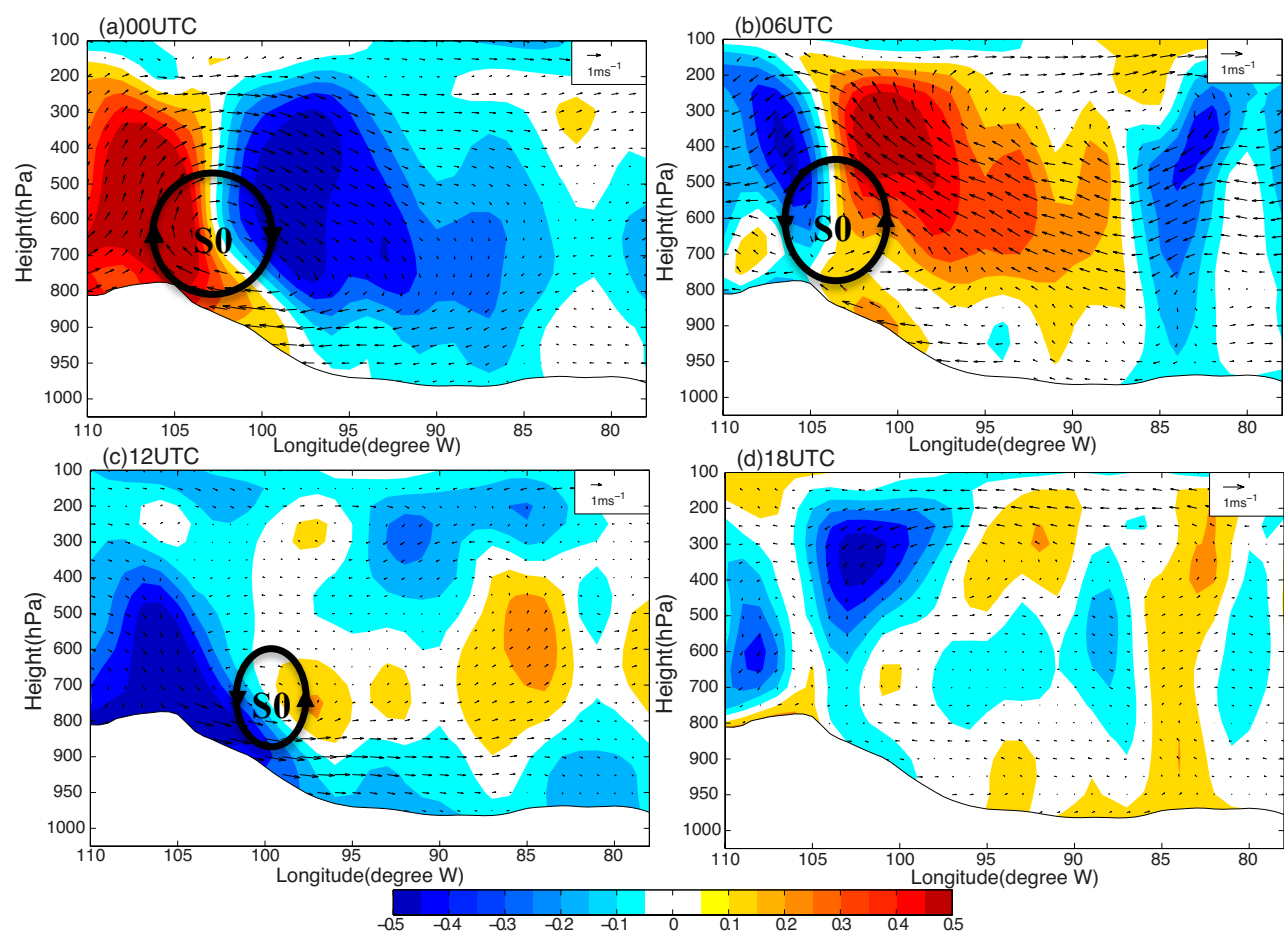

Figure 7. Similar to Fig. 6 but for the averages over the focus domain in North America. 

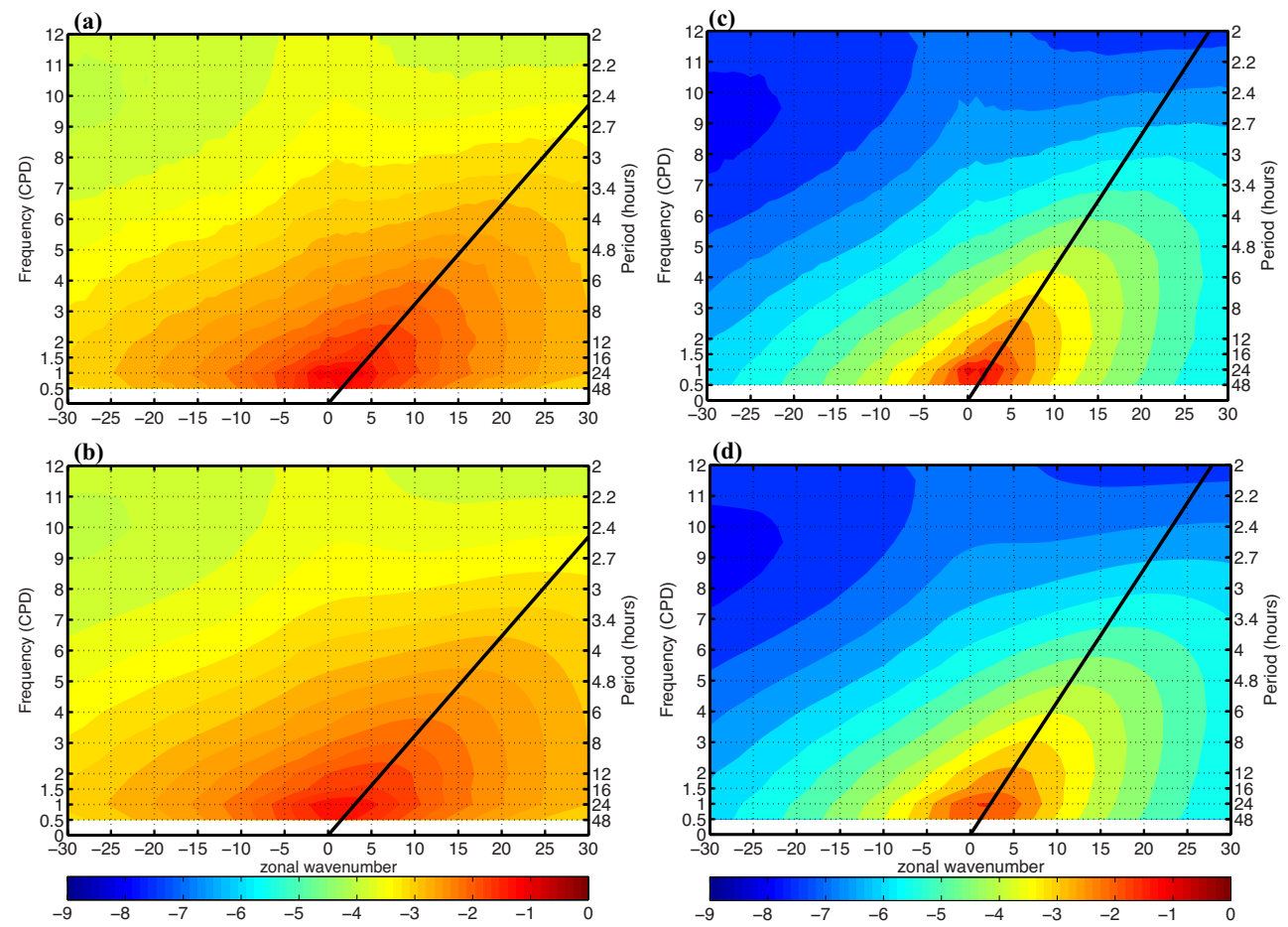

Figure 8. Top: zonal wave-number-frequency power spectra (with base-10 logarithmic transform) of the hourly precipitation throughout the warm season summed over the focus domains in (a) East Asia and (c) North America. Bottom: the same as in the left panels except for smoothed power spectra for (b) East Asia and (d) North America. The $y$ axis on the left is the frequency in units of CPD (cycle per day), and on the right the time period in hours. The black solid lines points out the ridges of power spectra.
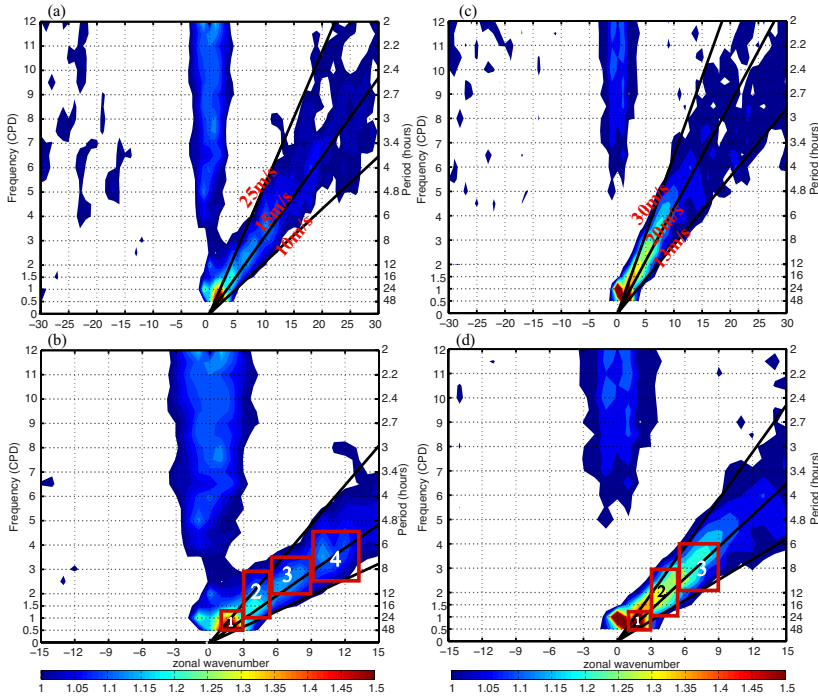

Figure 9. Top: normalized power spectra with raw values in Fig. 8a and $\mathrm{c}$ divided by smoothed values in Fig. $8 \mathrm{~b}$ and $\mathrm{d}$ for (a) East Asia and (c) North America. Bottom: as in the top panels but with zoomed-in display to include only wave numbers from -15 to 15 . The red rectangles denote for the spectral ranges from SR1 to SR4 described in Table 1. the maxima, shows four notable power peaks at zonal wave numbers $2,4,7$ and 10 and time periods $24,16,10$ and $6 \mathrm{~h}$, respectively. A similar situation is shown in North America (Fig. 9d), but the phase speed is from 13 to $30 \mathrm{~ms}^{-1}$, with a primary speed of $\sim 20 \mathrm{~ms}^{-1}$, which is also consistent with the eastward-propagating phase speed $\left(\sim 20 \mathrm{~m} \mathrm{~s}^{-1}\right)$ directly estimated from the Hovmöller diagram in Fig. 2b. The phase speeds calculated from the rain streak and duration in Fig. 15 of CAR02 are between 7 and $30 \mathrm{~ms}^{-1}$. In North America, the precipitation is less multi-scaled and the power maxima are at wave-numbers 2 and 5 . The power peak at wave-number 2 and time period $24 \mathrm{~h}$ illustrates that the diurnal variation in synoptic precipitation is the dominant signal, and the other peak appearing at wave-number 5 and time periods less than $10 \mathrm{~h}$ reveals that the precipitation with a zonal spatial scale of approximately $800 \mathrm{~km}$ and a temporal scale of $10 \mathrm{~h}$ also contributes to the local hourly precipitation. It is possible that the Meiyu front during the warm season and the more complicated terrain distribution of East Asia leads to more multi-scale and multi-modal precipitation. To exhibit the eastward propagation of different scales of precipitation, wave-number-frequency decomposition is used to filter the multi-scale precipitation. 

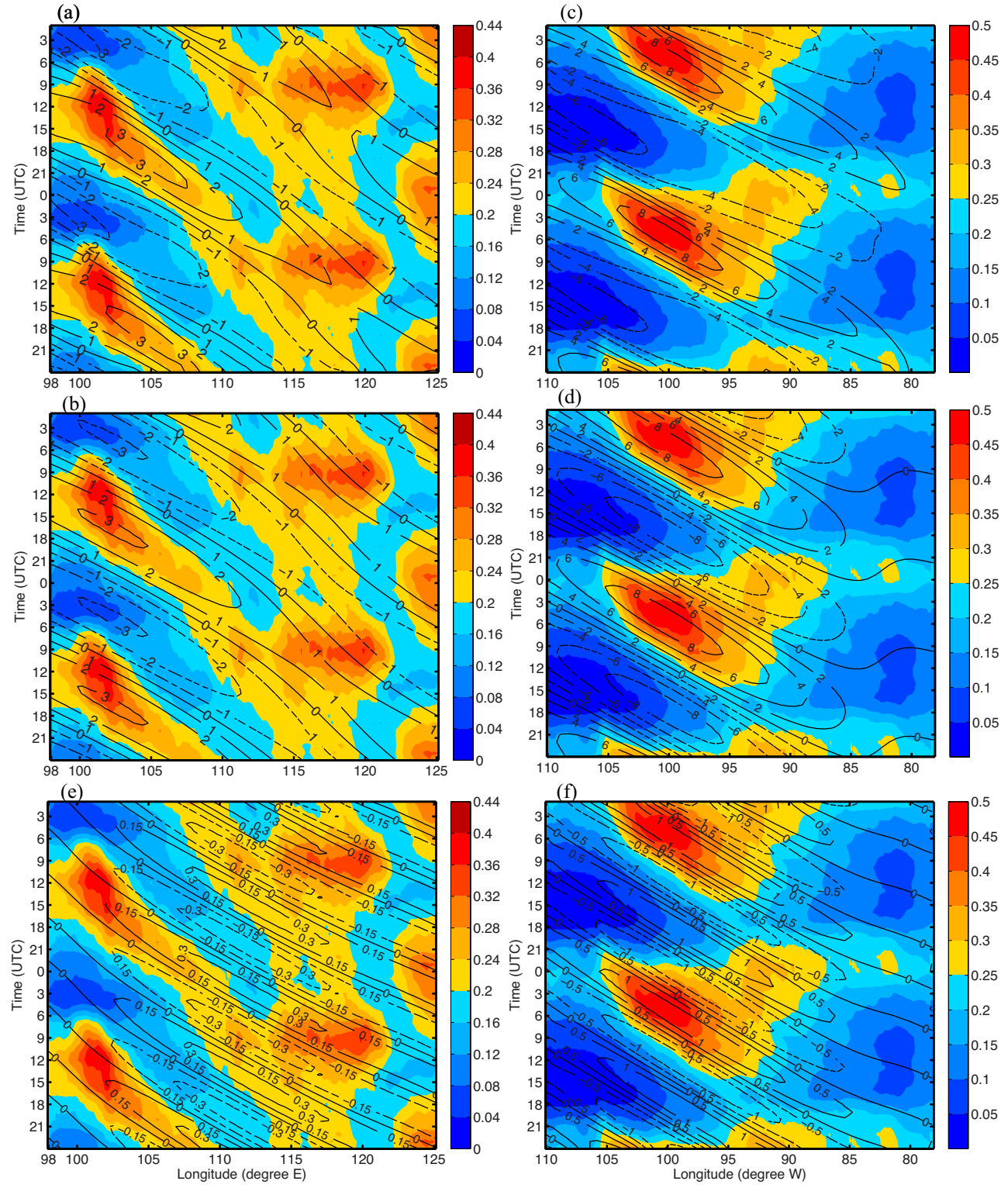

Figure 10. Left: the time-longitude diagram of the diurnal variation in the hourly precipitation (shadings, units: mm) and the filtered precipitation perturbation (multiplied by 100 , contours, units: $\mathrm{mmh}^{-1}$ ) in East Asia (a) spectrally filtered for phase speeds between 10 and $25 \mathrm{~ms}^{-1}$, (c) SR1 derived over the focus domain, values of contours are from -3 to 3 with interval of 1 , (c) SR 2 derived over the focus domain in East Asia, values of contours are from -0.3 to 0.3 with interval of 0.1 . Right: as in the left panels but in North America (d) for phase speeds between 13 and $30 \mathrm{~ms}^{-1}$, (e) SR 1 over the focus domain, values of contours are from -8 to 8 with interval of 2 , (f) SR 2 over the focus domain, values of contours are from -1 to 1 with interval of 0.5 .

\section{The multi-scale and multi-modal nature of precipitation}

Previous studies have revealed that the largest variances in daily precipitation come primarily from the diurnal and semidiurnal cycles (CAR02; Wang et al., 2004; Zhou et al., 2008; Huang and Chan, 2011, 2012; HZ10; BZS11). Figure 10a and $\mathrm{d}$ show the time-longitude diagrams of the diurnal variation in hourly precipitation (shadings) exhibiting eastward propagation similar to the normalized precipitation in Fig. 2 and precipitation perturbation ${ }^{4}$ filtered by the domain between the phase speed lines of 10 and $25 \mathrm{~ms}^{-1}$ in East Asia and 13 and $30 \mathrm{~ms}^{-1}$ in North America (contours, Fig. 9a, c). The filtered precipitation perturbation between phase speed lines is the primary eastward propagation signal compared with the raw hourly precipitation over both continents. The spatial distribution of the filtered precipitation perturbation

\footnotetext{
${ }^{4}$ The perturbation is derived from subtracting the mean wave (wave number $=0$ ) before inverse FFT process.
} 


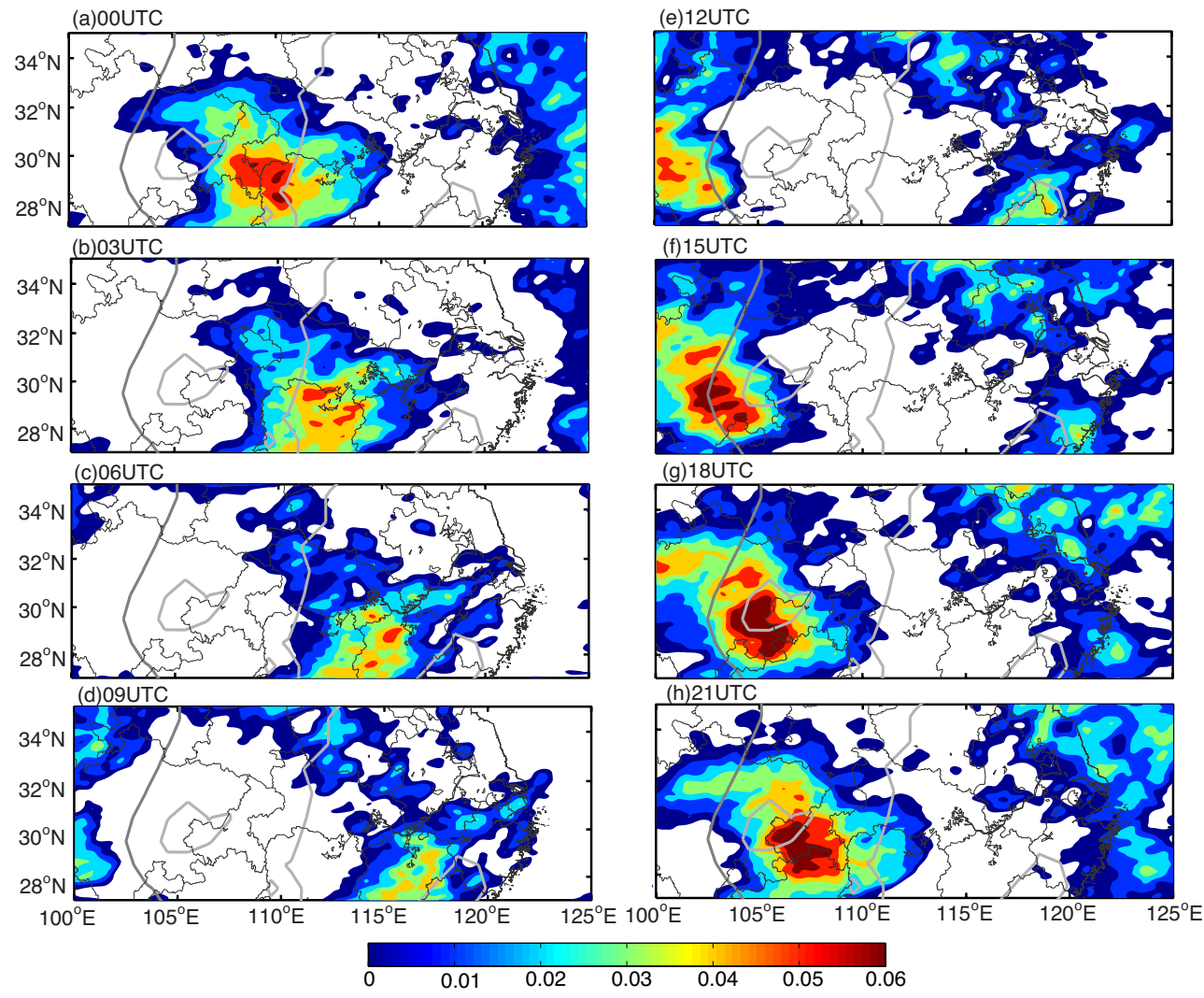

Figure 11. Similar to Fig. 3 but for the filtered precipitation perturbations (units: $\mathrm{mmh}^{-1}$ ) over the spectral range, bounded by the phase speed between 10 and $25 \mathrm{~ms}^{-1}$ over East Asia.

(Figs. 11 and 12) shows a similar diurnal phase of propagation to normalized hourly precipitation (Figs. 3 and 4, described in Sect. 3.1). Due to the precipitation perturbation filtered by the domain between phase-speed lines being the main eastward propagation signal, we next use 2-D spectral decomposition and filtering to examine several spectral ranges in frequency and wave number with enhanced relative spectral power (as noted in Fig. 9b and d and Table 1) to show the propagation features of precipitation of different spatial and temporal scale downstream of big topography over the two continents.

Spectral Range 1 (SR1) contains precipitation signals with zonal scales greater than $1000 \mathrm{~km}$ and wave periods between 18 and $48 \mathrm{~h}$, hereafter referred to as the synoptic-scale diurnal cycle. Spectral Range 2 (SR2) includes the precipitation signals with zonal scales between $800-1000 \mathrm{~km}$ and wave periods of $8-24 \mathrm{~h}$, hereafter referred to as the meso- $\alpha$ scale semi-diurnal cycle. Spectral Ranges 3 and 4 (SR3 and SR4) contain even smaller spatial and temporal scale rainfall signals, with zonal scales of several hundred kilometers and temporal scales of several hours. As will become evident in the following sections, these smaller scale signals are mostly due to smaller-scale mesoscale convective systems embed- ded within the larger scale active phases of the diurnal or seminal diurnal cycles.

\subsection{Propagating precipitation of the synoptic-scale diurnal cycle}

Figure $10 \mathrm{~b}-\mathrm{c}$ and e-f show the time-longitude diagrams of the diurnal variation in hourly precipitation (shadings) exhibiting eastward propagation similar to the normalized precipitation in Fig. 2 and filtered precipitation perturbation $^{5}$ (contours) within the first two spectral ranges (SR1, SR2). The filtered precipitation perturbation of the synopticscale diurnal cycle is the primary eastward propagation signal compared with the filtered precipitation perturbation between phase-speed lines (Fig. 10b). The spatial distribution of the filtered precipitation perturbation (Fig. 13) shows that the precipitation over the eastern edge of the TP $\left(98-100^{\circ} \mathrm{E}\right)$ in the afternoon (09:00-15:00 UTC, Figs. 10b and 13d-f) could propagate eastward at a phase speed of $\sim 19 \mathrm{~ms}^{-1}$ to the Sichuan Basin areas (approximately $105^{\circ} \mathrm{E}$ ) in the evening (18:00-21:00 UTC, Figs. 10b and 13g and h) and continues to move eastward to the second-step terrain (the

\footnotetext{
${ }^{5}$ The perturbation is derived from subtracting the mean wave (wave number $=0$ ) before inverse FFT process.
} 
Table 1. Wave-number-frequency filter domains shown in Fig.9b and d.

\begin{tabular}{ccccc}
\hline \multirow{2}{*}{ Filter Domain } & \multicolumn{2}{c}{ Wave number/Wavelength(km) } & \multicolumn{2}{c}{ Frequency(CPD)/Period (hour) } \\
& East Asia & North America & East Asia & North America \\
\hline SR1 & $1-3 / 1400-4000$ & $1-3 / 1400-4000$ & $0.75-0.5 / 18-48$ & $0.75-0.5 / 18-48$ \\
SR2 & $3-5 / 800-1400$ & $3-5 / 800-1400$ & $3.0-1.0 / 8-24$ & $3.0-1.0 / 8-24$ \\
SR3 & $5-9 / 500-800$ & $5-9 / 500-800$ & $3.4-2.0 / 7-12$ & $4.0-2.0 / 6-12$ \\
SR4 & $9-13 / 300-500$ & N/A & $4.8-2.7 / 5-9$ & N/A \\
\hline
\end{tabular}

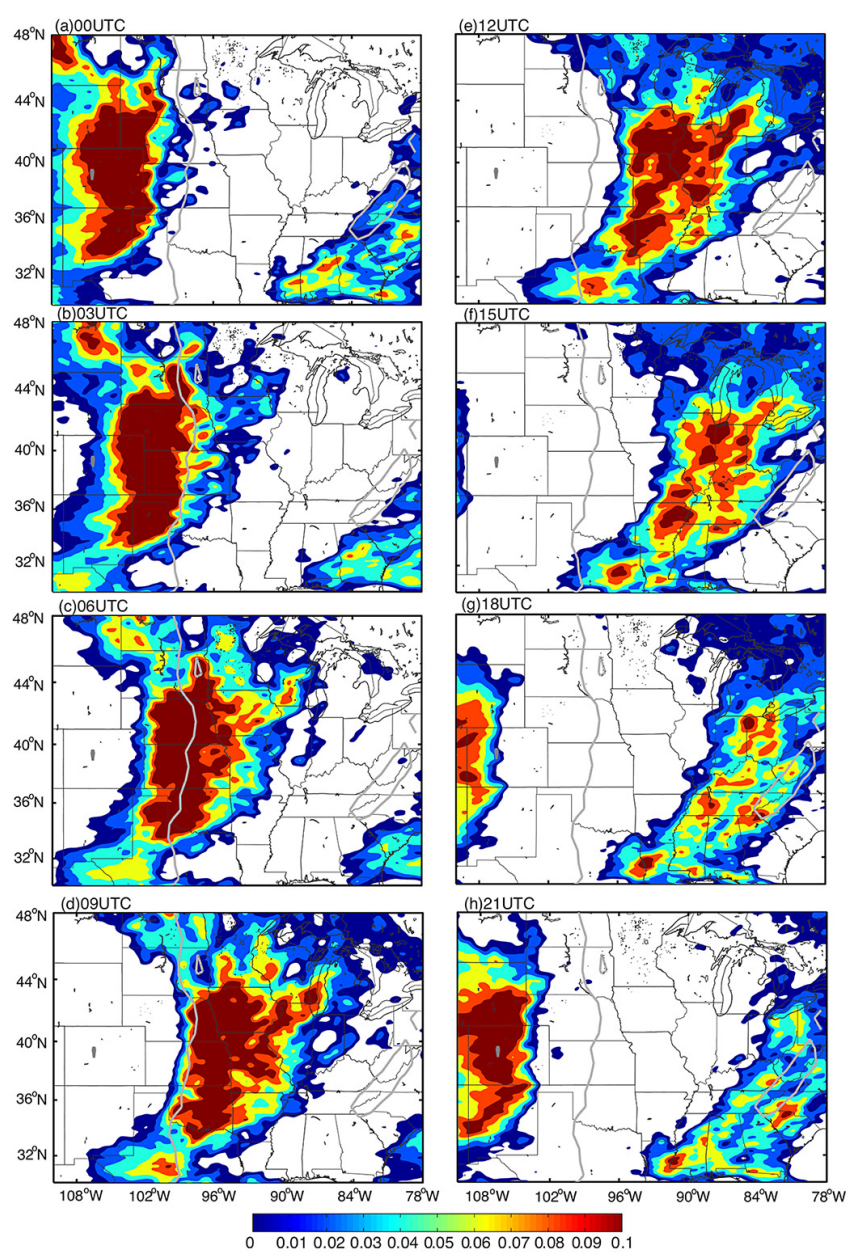

Figure 12. Similar to Fig. 3 but for the filtered precipitation perturbations (units: $\mathrm{mmh}^{-1}$ ) over the spectral range bounded by the phase speed between 13 and $30 \mathrm{~ms}^{-1}$ over North America.

Wushan and Qingling Mountains, $\left.107-110^{\circ} \mathrm{E}\right)$ in the morning (00:00-03:00 UTC, Figs. 10b and 13a and b), consistent with the diurnal phase propagation of the normalized hourly precipitation (Fig. 3).

After propagating across the second-step terrain, the filtered perturbation splits into the southern part (south of $30^{\circ} \mathrm{N}$ ) and the northern part (north of $30^{\circ} \mathrm{N}$ ). The northern part is furthermore increased by the precipitation perturbation originating from the mountain ranges in northern China
(HZ10, BZS11). The power spectra show that the eastwardpropagating precipitation perturbation over the northern area propagates slightly faster than the southern one (Fig. 14a and b), which is consistent with the results obtained by Wang et al. (2005). Meanwhile, the vertical profile of the zonal wind speed averaged over the two areas also illustrates that the steering wind speed at levels upper than $500 \mathrm{hPa}$ over the northern area is much larger than the southern wind speed, but the wind speed at levels lower than $500 \mathrm{hPa}$ over the southern area is slightly larger than the northern wind speed possibly because of the southwestern low level jet (LLJ, wind fields in lower levels are not shown). Over the eastern low-lying plains, enhanced precipitation in the northern area causes late-evening-to-early-morning rainfall over the YHRV, and the southern part shows an afternoon-to-earlyevening precipitation maximum over southern China (06:0018:00 UTC, Fig. 13c-g). Finally, the southern and northern parts combine together, moving to the eastern coastline areas in the early morning (18:00-00:00 UTC, Fig. 13g-a).

The diurnal variation of hourly precipitation and the filtered precipitation perturbation within SR1 during the warm season over North America is shown in Figs. 10e and 15. Similar to the eastward-propagating precipitation over East Asia, the precipitation originates from the eastern edge of the Rocky Mountains (approximately $105^{\circ} \mathrm{W}$ ) in the afternoon (18:00-00:00 UTC, Figs. 10e and 15a-g), migrates eastward to the downslope in the evening (03:00-06:00 UTC, Figs. 10e and $15 \mathrm{~b}$ and $\mathrm{c}$ ) and propagates to the central plains (approximately $90^{\circ} \mathrm{W}$ ) in the early morning (09:00-15:00 UTC, Figs. 10e, and $15 \mathrm{~d}-\mathrm{f}$ ) at a phase speed of $25 \mathrm{~ms}^{-1}$. Finally, the precipitation maximum shifts to a northeast-southwest orientation and propagates southeastward to the southeastern coastline areas in the afternoon to evening (18:0006:00 UTC, Figs. 10e and 15c-g). As discussed in Sect. 3, the dominant MPS circulation over North America covers a range of $\sim 2000 \mathrm{~km}$, which is within the spatial scale of SR1. The maximum precipitation at 00:00 and 06:00 UTC (Figs. 15a and c) corresponds to the branches of upward motion of the MPS circulations in Fig. 7a and b.

The phase speed of the filtered precipitation perturbation within SR1 over North America is faster than that over East Asia possibly because the wind speed of the ambient westerlies over the former continent is higher than that over the latter continent from the lower to upper levels, which is 


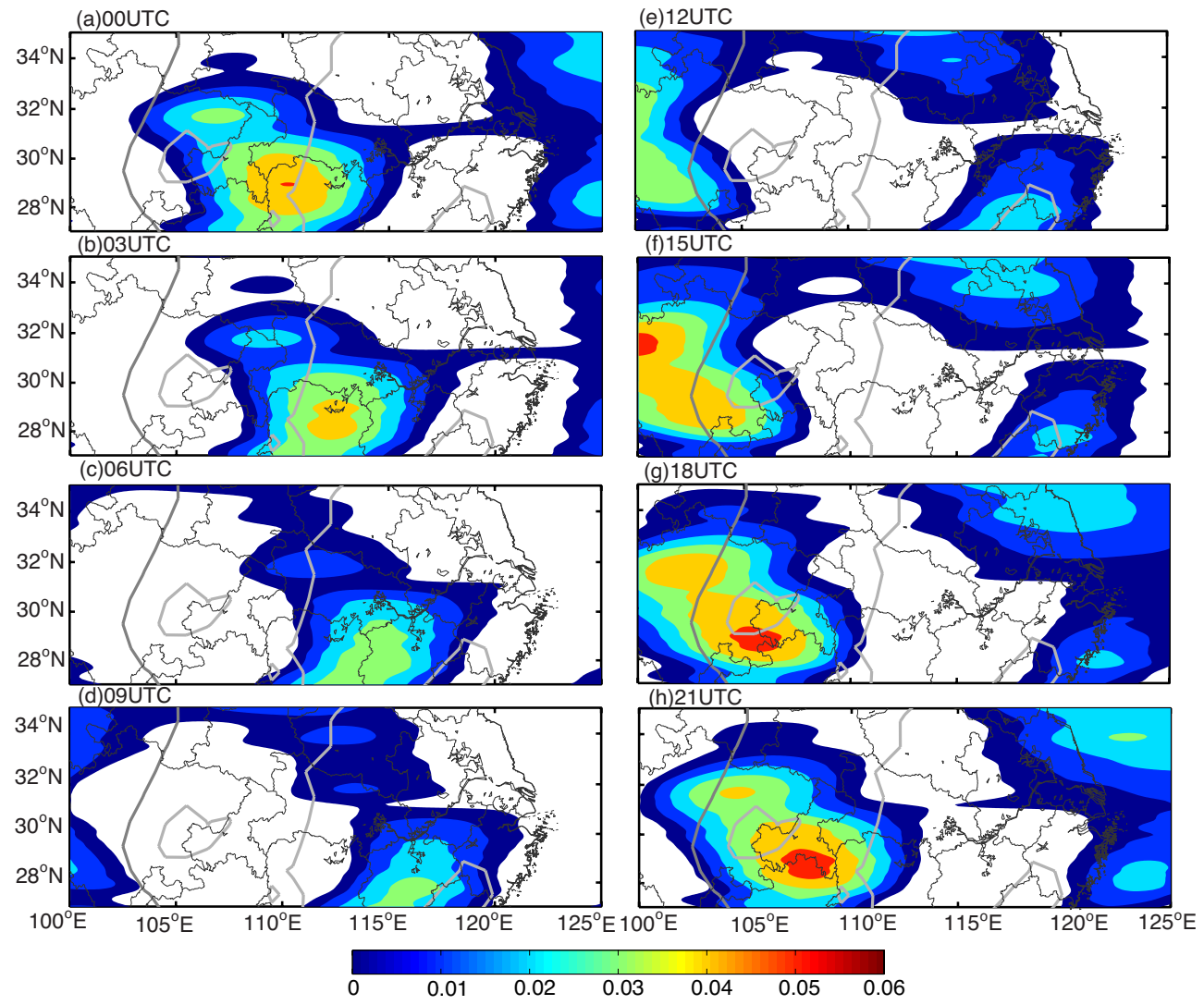

Figure 13. Similar to Fig. 3 but for the filtered precipitation perturbations (units: $\mathrm{mmh}^{-1}$ ) over spectral range \#1 (SR1) for periods between $18-48 \mathrm{~h}$ and zonal wavelengths between $1400-4000 \mathrm{~km}$ over East Asia.
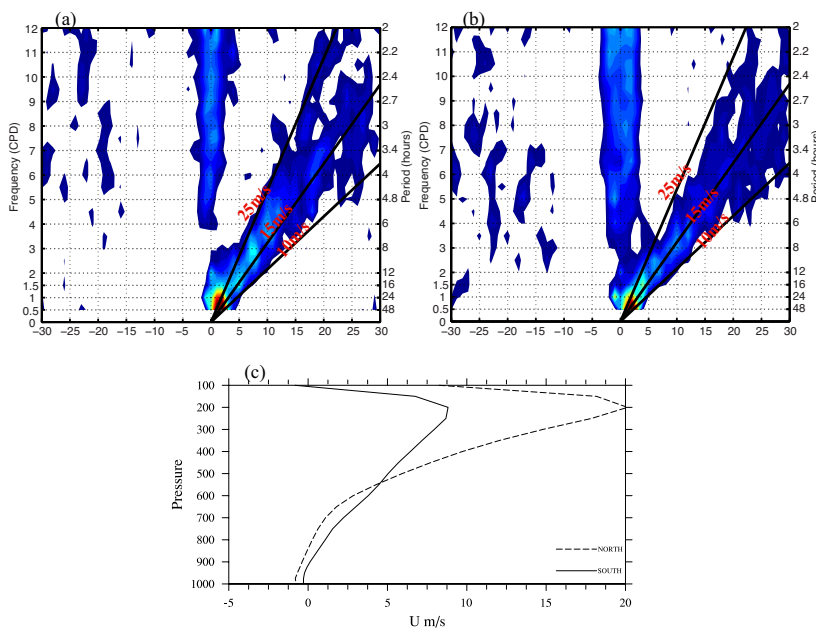

Figure 14. Top: similar to Fig. 9 but calculated over (a) north of $30^{\circ} \mathrm{N}$ and (b) south of $30^{\circ} \mathrm{N}$ for the focus domain in East Asia. (c) Vertical profile of areal mean zonal wind speed averaged over the northern and southern part of the focus domain in East Asia. consistent with the total propagation speed in Fig. 5. Although the terrain distribution in the mid-latitude regions east of the TP in East Asia is more complex than that in the areas east of the Rocky Mountains in North America, the synopticscale diurnal cycles of precipitation have similar propagation characteristics, except that the filtered precipitation perturbation east of the Rocky Mountains moves eastward faster than that east of the TP and that the early morning precipitation from the second-step terrain in northern China increases over the YHRV. Additionally, the continental scale MPS circulation over North America relates to the zonal synoptic eastward-propagating precipitation.

\subsection{The propagating precipitation of the meso- $\alpha$-scale semi-diurnal cycle}

Based on the spectral calculation method introduced in Sect. 2, this study highlights diurnal and semi-diurnal variation of precipitation. SR2 is used to analyze semi-diurnal variation of precipitation at a zonal scale of approximately $1000 \mathrm{~km}$ (meso- $\alpha$ scale). In contrast with diurnal cycle, strong semi-diurnal variation of filtered maximum precipitation perturbation occurs primarily from the second-step terrain to the eastern low-lying plain and propagates eastward 


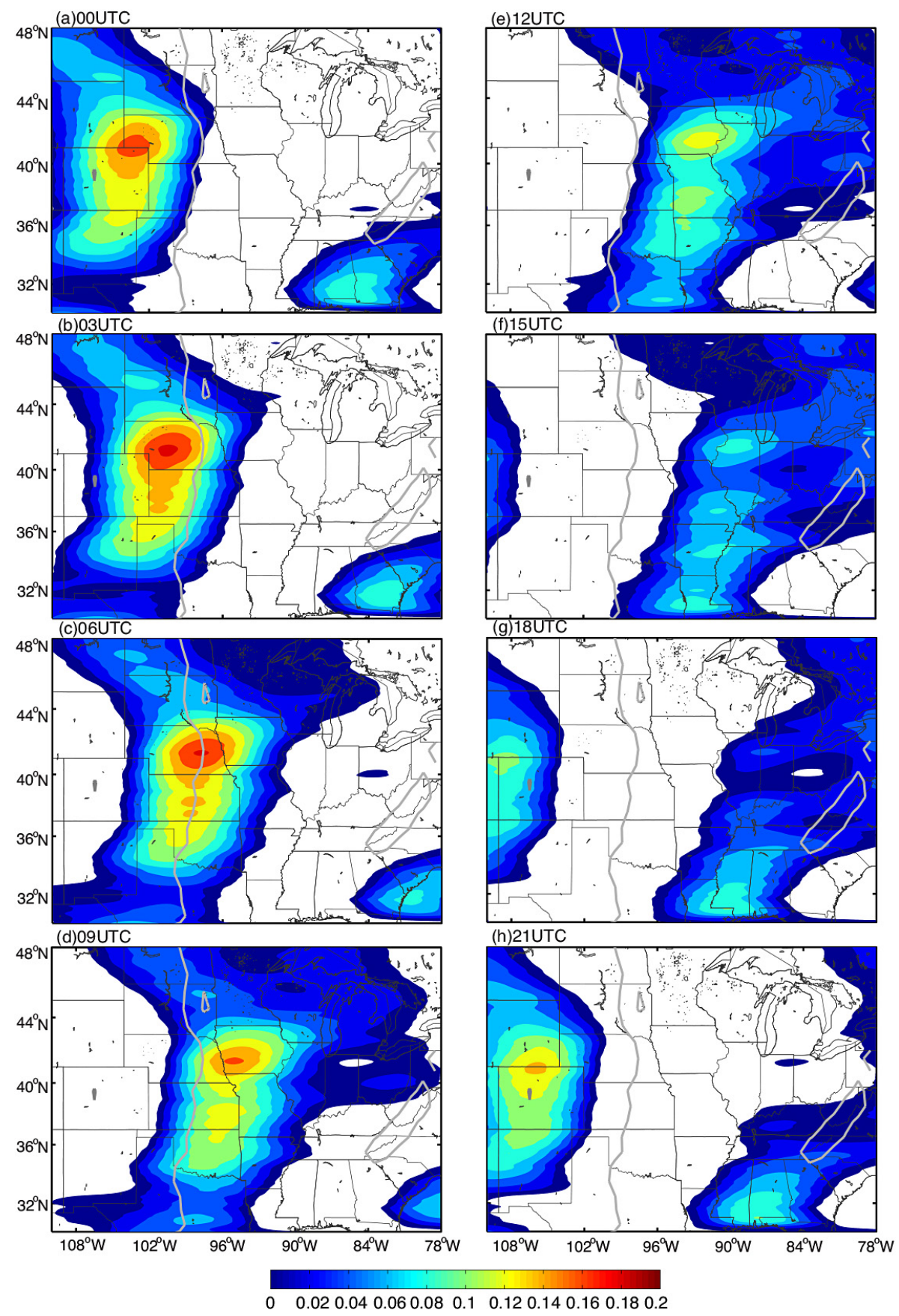

Figure 15. Similar to Fig. 13 but for SR1-filtered perturbations (units: $\mathrm{mmh}^{-1}$ ) over North America.

at a phase speed of approximately $22 \mathrm{~ms}^{-1}$ (Fig. 10c). The semi-diurnal cycle has two local precipitation peaks (Fig. 16). The peak originating over the eastern edge of the TP in the early evening (12:00-15:00 UTC, Figs. 10c and 16e and f) propagates eastward to the Sichuan Basin in the late evening to early morning (18:00 UTC, Figs. $10 \mathrm{c}$ and $16 \mathrm{~g}$ ). The peak continues to move eastward to the second-step terrain in the morning (21:00-00:00 UTC, Figs. 10c and 16a-h) and arrives at the eastern plains in the afternoon (06:00-
09:00 UTC, Figs. 10 and $16 \mathrm{c}$ and d). The other peak appears $12 \mathrm{~h}$ earlier than that described above. The semi-diurnal cycle of meso- $\alpha$ precipitation perturbation (SR2) coupled with the upward motion of the MPS circulations (06:00 and 18:00 UTC, Figs. 6b and d) increases the local hourly precipitation over the YHRV $\left(115-120^{\circ} \mathrm{E}\right)$ in the daytime and over the low-lying basin at night $\left(105-108^{\circ}\right.$ E, Figs. $16 \mathrm{c}$ and g). Huang and Chan (2012) studied the relationship between the semi-diurnal cycle of precipitation and clouds and showed 


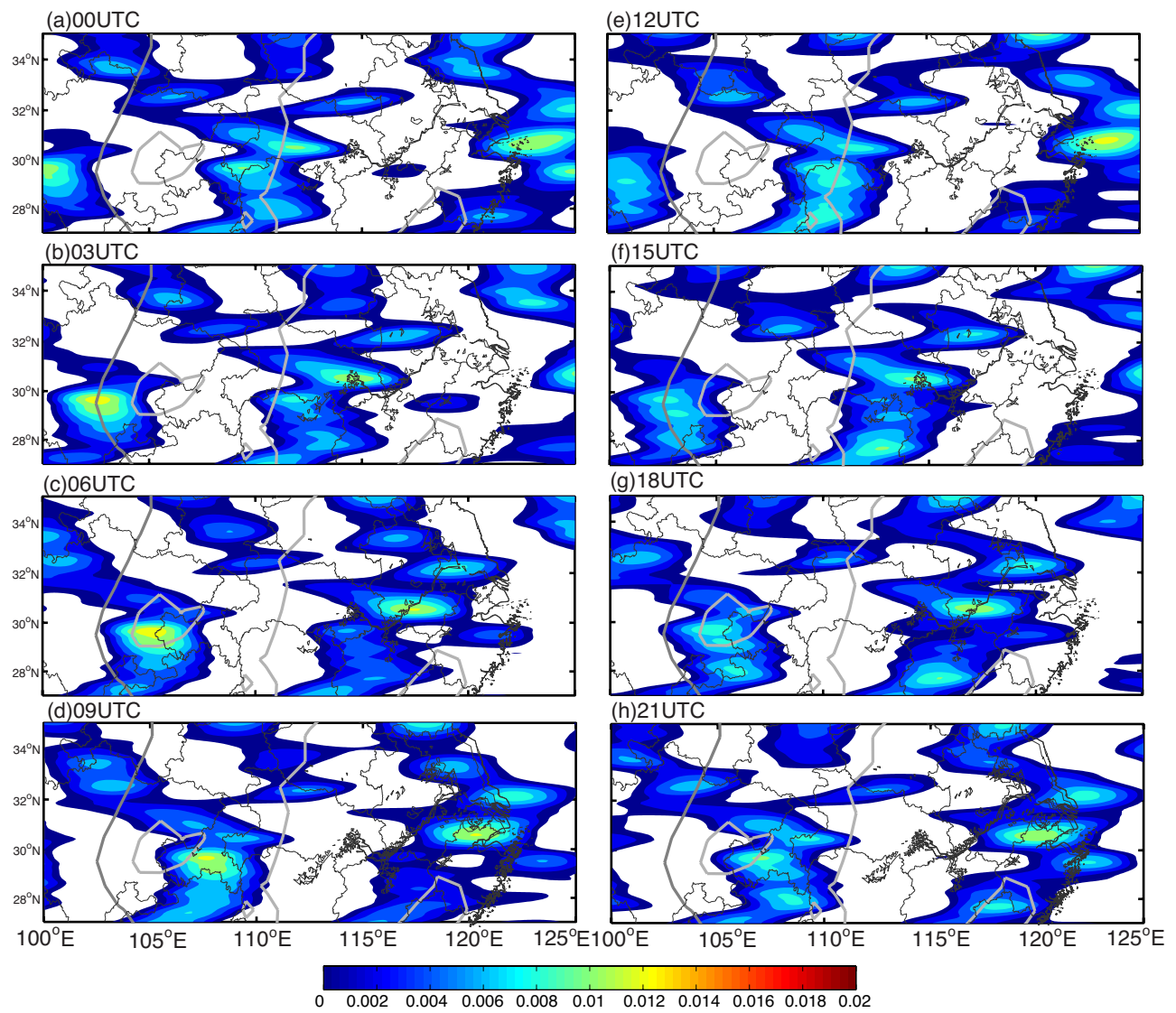

Figure 16. Similar to Fig. 11 but for SR2-filtered perturbations (units: $\mathrm{mmh}^{-1}$ ) over East Asia for periods between $8-24 \mathrm{~h}$ and zonal wavelengths between $800-1400 \mathrm{~km}$.

that the radiation effect of clouds is likely to cause the phase of the semi-diurnal net radiative heating/cooling cycle over southeastern China (SEC). Additionally, over SEC, the semidiurnal maxima occur at 09:00 and 21:00 UTC, which is similar to the timing of the maximum precipitation over SEC in Figs. 16d and h. The possible relationship between the semi-diurnal cycle of precipitation and the net radiation of mid-level and high-level clouds need to be confirmed in future work using model output high-resolution data.

Figures 10f and 17 show the filtered precipitation perturbation within SR2 over North America. The obvious precipitation perturbation occurs from the eastern edge of the Rocky Mountains to the eastern plains in the late evening to early morning and afternoon $\left(95-90^{\circ} \mathrm{W}, 06: 00-09: 00\right.$ UTC and 18:00-21:00 UTC) and propagates eastward to $83^{\circ} \mathrm{W}$ in the following late evening and afternoon (03:00-06:00 and 15:00-18:00 UTC) at a speed of $\sim 25 \mathrm{~ms}^{-1}$. The map distribution within SR3 (Fig. 17) also has an apparent semi-diurnal cycle, and the strong phase of the semi-diurnal variation propagates from the eastern edge of the Rocky Mountains to the central plains (west of $90^{\circ} \mathrm{W}$ ). However, the precipitation over the eastern domain (east of $90^{\circ} \mathrm{W}$ ) of North America exhibits a weak semi-diurnal phase. Combining with precipita- tion filtered within SR1, the maximum rainfall appears over the eastern edge of the Rocky Mountains in the afternoon and over the central plain in the evening.

The analysis of the filtered precipitation perturbation within SR2 indicates that the semi-diurnal cycle shifts relatively little from west to east, with two daily precipitation peaks over both continents: one appearing in the daytime and the other occurring at night. Under the influence of the MPS circulations, the local hourly precipitation maxima over the mountains or highlands appears in the afternoon to early evening while the precipitation peak over the eastern plains occurs in the late evening to early morning.

\subsection{Filtered precipitation at smaller spatial scales and higher frequencies}

We have identified four spectral ranges (SRs) in East Asia and three filter SRs in North America in Fig. 9b and d, and the first two SRs have been discussed in previous sections. SR3 and SR4 in Fig. 9b include precipitation of the zonal spatial scale, between 300 and $800 \mathrm{~km}$, and wave periods from 5 to $12 \mathrm{~h}$. Figure $18 \mathrm{a}$ and b shows the hourly precipitation variance filtered by SR3 and SR4 over East Asia. A 

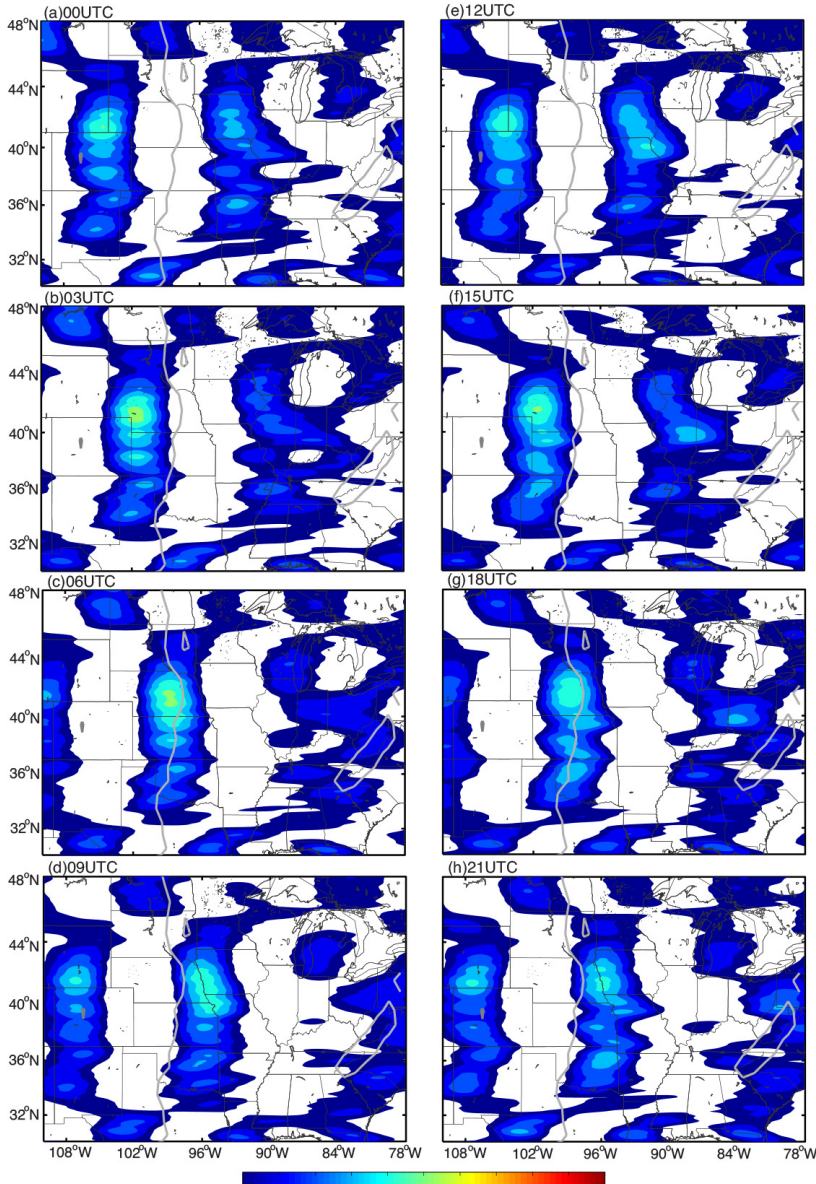

Figure 17. Similar to Fig. 14 but for SR2-filtered perturbations (units: $\mathrm{mmh}^{-1}$ ) over North America.

large variance in filtered hourly precipitation follows along the eastward propagation of the raw rainfall. Two maxima of variance appears at the eastern edge of the TP and in the regions from the eastern downslope of the second-step terrain to the YHRV, which indicates that precipitation or convection of several hundred kilometers and several hours is triggered in a phase of strong precipitation. Figure $18 \mathrm{c}$ shows the variance in the filtered hourly precipitation over North America with SR3. Similar to Fig. 18a and b, precipitation with a zonal spatial wavelength from 500 to $800 \mathrm{~km}$ and a temporal scale of $6-12 \mathrm{~h}$ primarily occurs at the eastern edge of the Rocky Mountains $\left(100-92^{\circ} \mathrm{W}\right)$ within the strong diurnal precipitation.

\section{Concluding remarks}

This study uses the wave-number-frequency spectral decomposition technique to analyze the high-resolution CMORPH precipitation data set and to present the differences and similarities of the diurnal variation in extratropical precipitation
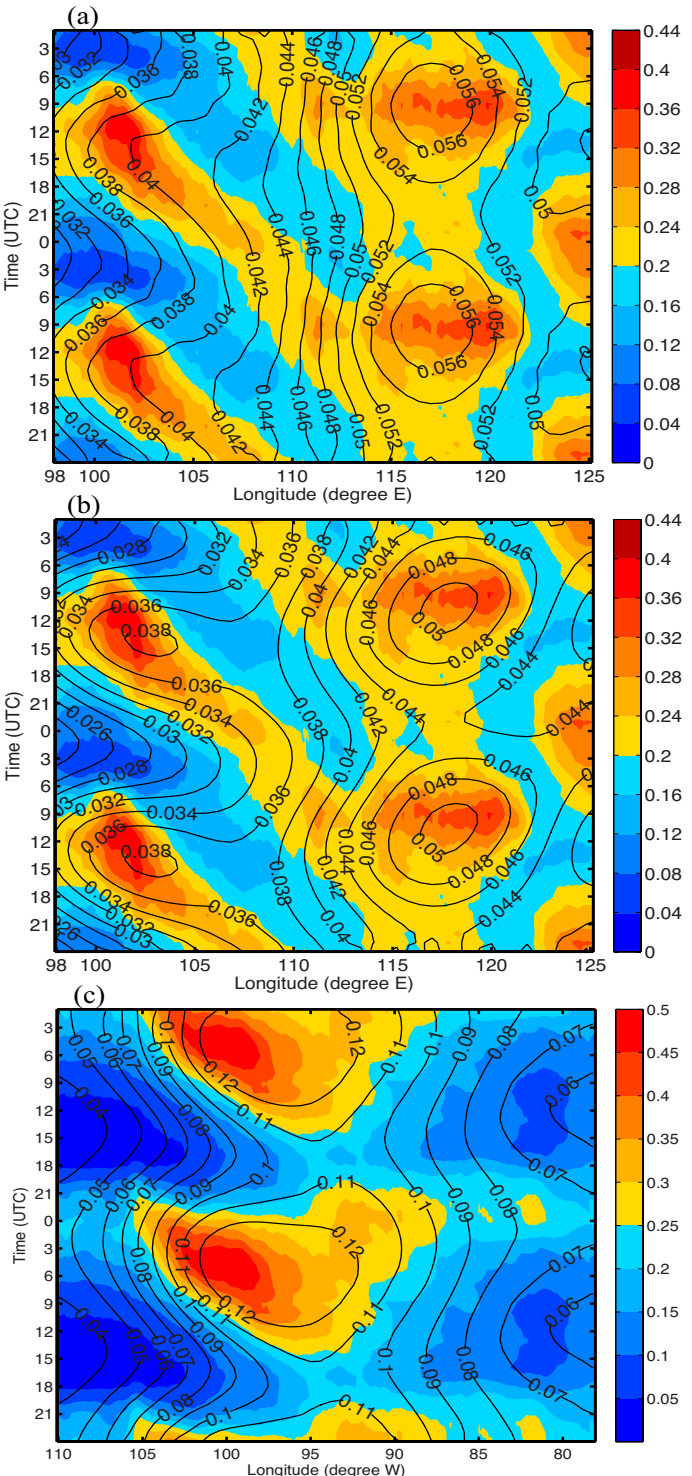

Figure 18. Time-longitude diagram of the diurnal variation in the hourly precipitation (shadings, units: $\mathrm{mmh}^{-1}$ ) and the filtered precipitation perturbation variances (contours) for (a) SR3 and (b) SR4 over East Asia, contours interval is 0.02 and (c) for with SR3 for North America, contours interval is 0.01 .

during the warm season from 2003 to 2010 in East Asia and North America. Precipitation on both continents exhibits an obvious eastward-propagating signal from the eastern edge of the TP/the Rocky Mountains to the downslope areas and local afternoon precipitation maxima on the low-lying plains. The phase speed of the propagating precipitation in North America is faster than that of East Asia, which is at least partially influenced by a higher mean speed of the ambient westerlies. 
Power spectral analysis shows obvious eastward propagation of the hourly precipitation in the wave-numberfrequency domain over the two continents. The eastwardpropagating phase-speeds range from 10 to $25 \mathrm{~ms}^{-1}$ in East Asia and from 13 to $30 \mathrm{~ms}^{-1}$ in North America, generally consistent with previous studies (Wang et al., 2004, 2005; CAR02).

The decomposition results show that the precipitation of the synoptic-scale diurnal cycle is the dominant eastward-propagating signal from the eastern edge of both the TP and the Rocky Mountains in the afternoon to their low-lying areas in the evening, but the propagating phase speed $\left(\sim 25 \mathrm{~ms}^{-1}\right)$ in North America is faster than the $\sim 19 \mathrm{~ms}^{-1}$ in East Asia. Furthermore, the precipitation splits into southern and northern parts after moving across the second-step terrain in East Asia. The northern portion of the precipitation originating from the eastern edge of the TP merges with that which propagates from the Taihangshan Mountains in northern China and causes the early morning precipitation over the YHRV, whereas the southern portions of the precipitation propagates eastward in southwestern China in the evening. The precipitation of the meso- $\alpha$ scale diurnal cycle migrates eastward at a slower phase speed compared with the larger scale precipitation over both continents. The upward motion of the MPS circulation (S2) between the second-step terrain and its low-lying areas couples with the eastward-propagating precipitation. In contrast, in North America, the maximum precipitation gradually decreases with the eastward propagation. The precipitation of meso- $\alpha$-scale semi-diurnal cycle couples with diurnal cycle of the synoptic precipitation and causes the diurnal maximum precipitation over the highlands or mountains and the nocturnal rainfall peak over the plains or basins. The filtered precipitation on a scale of several hundred kilometers and time periods of several hours indicates that smaller scale precipitation is evident in the active phase of the dominant diurnal cycle.

This study is limited in its precipitation analysis by a lack of detail regarding the dynamics. Case simulation will be used to analyze the multi-scale precipitation using high spatial and temporal resolution data in future work. The decomposition method will be applied in the dynamic analysis to explain the reasons for the propagation characteristics of the precipitation within different spatial and temporal scales. Trier et al. (2010) examined the MPS circulation and its relationship to the diurnal cycle of precipitation in North America, while Bao and Zhang (2013) examined similarly for northern China. Both studies found that the propagation and maintenance of the precipitation peak over the plains can be influenced by the steering-level mean flow, the evolution of the MPSs, and the cold pool dynamics. The comparison of the diurnal variation in precipitation over different latitude ranges of the current focus domains would also be considered in future studies.
Acknowledgements. This study was supported by the National Key Basic Research and Development Project of China (no. 2012CB417201), the National Natural Science Foundation of China (grant no. 40930951) and the US National Science Foundation (grant no. 1114849).

Edited by: H. Wernli

\section{References}

Bao, X., Zhang, F., and Sun, J.: Diurnal variations of warmseason precipitation east of the Tibetan Plateau over China, Mon. Weather Rev., 139, 2790-2810, 2011.

Carbone, R. E. and Tuttle, J. D.: Rainfall occurrence in the United States warm season: the diurnal cycle, J. Climate, 21, 41324136, 2008.

Carbone, R. E., Tuttle, J. D., Ahijevych, D., and Trier, S. B.: Inferences of predictability associated with warm season precipitation episodes, J. Atmos. Sci., 59, 2033-2056, 2002.

Chen, G., Sha, W., and Iwasaki, T.: Diurnal variation of precipitation over southeastern China: Spatial distribution and its seasonality, J. Geophys. Res., 114, D13103, doi:10.1029/2008JD011103, 2009.

Dai, A. and Wang, J.: Diurnal and semidiurnal tides in global surface pressure fields, J. Atmos. Sci., 56, 3874-3891,1999.

Dai, A., Giorgi, F., and Trenberth, K. E.: Observed and modelsimulated diurnal cycles of precipitation over the contiguous United States, J. Geophys. Res., 104, 6377-6402, 1999.

Ding, Y.: Study on the lasting heavy rainfalls over the YangtzeHuaihe river basin in 1991, China Meteorological Press, Beijing, 255 pp., 1993 (in Chinese).

Geng, B. and Yamada, H.: Diurnal variations of the Meiyu/Baiu rain belt, SOLA, 3, 61-64, 2007.

Hayashi, Y.: Space-time spectral analysis and its applications to atmospheric waves, J. Meteorol. Soc. Jpn., 60, 156-171, 1982.

He, H. and Zhang, F.: Diurnal variations of warm-season precipitation over North China, Mon. Weather Rev., 138, 1017-1025, 2010.

Huang, H. L., Wang, C. C., Chen, G. T. J., and Carbone, R. E.: The Role of diurnal solenoidal circulation on propagating rainfall episodes near the eastern Tibetan Plateau, Mon. Weather Rev., 138, 2975-2989, 2010.

Huang, W. R. and Chan, C. L.: Maintenance mechanism for the early-morning maximum summer rainfall over Southeast China, Q. J. R. Meteorol. Soc., 137, 959-986, 2011.

Huang, W. R. and Chan, C. L.: Seasonal variation of diurnal and semidiurnal rainfall over Southeast China, Clim. Dynam., 39, 1913-1927, 2012.

Joyce, R. J., Janowiak, J. E., and Arkin, P. A., and Xie, P.: CMORPH: A method that produces global precipitation estimates from passive microwave and infrared data at high spatial and temporal resolution, J. Hydrometeorol., 5, 487-503, 2004.

Lane, T. P. and Zhang, F.: Coupling between gravity waves and tropical convection at mesoscales, J. Atmos. Sci., 68, 2582-2598, 2011.

Koch, S. E., Zhang, F., Kaplan, M. L., Lin, Y.-L., Weglarz, R., and Trexler, C. M.: Numerical simulations of a gravity wave event over CCOPE. Part III: The role of a mountain-plains solenoid in 
the generation of the second wave episode, Mon. Weather Rev., 129, 909-933, 2001.

Kurosaki Y. and Kimura, F.: Relationship between topography and daytime cloud activity around Tibetan Plateau, J. Meteorol. Soc. Jpn., 80, 1339-1355, 2002.

Ninomiya, K.: Large- and meso-a-scale characteristics of MeiyuBaiu front associated with intense rainfalls in 1-10 July 1991, J. Meteorol. Soc. Jpn., 78, 141-157, 2000.

Sun, J. and Zhang, F.: Impacts of mountain-plains solenoid on diurnal variations of rainfalls along the Mei-yu front over the East China plains, Mon. Weather Rev., 140, 379-397, 2012.

Sun, J., Zhao, S. X., Xu, G. K., and Meng, Q. T.: Study on a mesoscale convective vortex causing heavy rainfall during the Meiyu season in 2003, Adv. Atmos. Sci., 27, 1193-1209, 2010.

Tao, S. Y.: Rainstorm in China, Science Press, Beijing, 225 pp., 1980 (in Chinese).

Trier, S. B., Davis, C. A., Ahijevych, D. A., Weisman, M. L., and Bryan, G. H.: Mechanisms supporting long-lived episodes of propagating nocturnal convection within a 7-day WRF model simulation, J. Atmos. Sci., 63, 2437-2461, 2006.

Trier, S. B., Davis, C. A., and Ahijevych, D. A.: Environmental controls on the simulated diurnal cycle of warm-season precipitation in the continental United States, J. Atmos. Sci., 67, 1066-1090, 2010.

Tripoli, G. J. and Cotton, W. R. : Numerical study of an observed orogenic mesoscale convective system. Part I: Simulated genesis and comparison with observations, Mon. Weather Rev., 117, 273-304, 1989a.

Wang, C. C., Chen, G. T. J., and Carbone, R. E.: A climatology of warm-season cloud patterns over east Asia based on GMS infrared brightness temperature observations, Mon. Weather Rev., 132, 1606-1629, 2004.

Wang C. C., Chen, G. T. J., and Carbone, R. E.: Variability of warmseason cloud episodes over east Asia based on GMS infrared brightness temperature observations, Mon. Weather Rev., 133, 1478-1500, 2005.
Wheeler M. and Kiladis, G. N.: Convectively coupled equatorial waves: analysis of clouds and temperature in the wavenumberfrequency domain, J. Atmos. Sci., 56, 374-399, 1999.

Xinghua Bao and Fuqing Zhang: Impacts of the mountain-plains solenoid and cold pool dynamics on the diurnal variation of warm-season precipitation over northern China, Atmos. Chem. Phys., 13, 6965-6982, doi:10.5194/acp-13-6965-2013, 2013.

$\mathrm{Xu}, \mathrm{W}$. and Zipser, E. J.: Diurnal variations of precipitation, deep convection, and lightning over and east of the Eastern Tibetan Plateau. J. Climate, 24, 448-465, 2011.

Xu, W., Zipser, E. J., and Liu, C.: Rainfall characteristics and convective properties of mei-yu precipitation systems over South China, Taiwan and the South China Sea. Part I: TRMM observations, Mon. Weather Rev., 137, 4261-4275, 2009.

Yasunari, T. and Miwa, T.: Convective cloud systems over the Tibetan Plateau and their impact on Meso-scale disturbance in the Meiyu/Baiu frontal zone, J. Meteorol. Soc. Jpn., 84, 783-803, 2006.

Yu, R. C., Zhou, T. J., Xiong, A., Zhu, Y., and Li, J.: Diurnal variations of summer precipitationover contiguous China, Geophys Res. Lett., 34, L01704, doi:10.1029/2006GL028129, 2007.

Yu, R. C., Li, J., and Chen H.: Diurnal variation of surface wind over central eastern China, Climate Dyn., 33, 1089-1097, 2009.

Zhang, F. and Koch, S. E.: Numerical simulation of a gravity wave event observed during CCOPE. 2: Wave generation by an orographic density current, Mon. Weather Rev., 128, 2777-2796, 2000.

Zhou, T., Yu, R., Chen, H., Dai, A., and Pan, Y.: Summer precipitation frequency, intensity, and diurnal cycle over China: A comparison of satellite data with rain gauge observations, J. Climate., 21, 3997-4010, 2008. 